A função logaritmo e a régua de cálculo

Tania Cristina Maggioni Pippa 

SERVIÇO DE PÓS-GRADUAÇÃO DO ICMC-USP

Data de Depósito: 8 de maio de 2014.

Assinatura:

\title{
A função logaritmo e a régua de cálculo
}

\section{Tania Cristina Maggioni Pippa}

\author{
Orientador: Prof. Dr. Luiz Augusto da Costa Ladeira
}

\begin{abstract}
Dissertação apresentada ao Instituto de Ciências Matemáticas e de Computação - ICMC-USP, como parte dos requisitos para obtenção do título de Mestre - Programa de Mestrado Profissional em Matemática. VERSÃO REVISADA (impressa).
\end{abstract}


Autorizo a reprodução e divulgação total ou parcial deste trabalho, por qualquer meio convencional ou eletrônico, para fins de estudo e pesquisa, desde que citada a fonte.

Ficha catalográfica elaborada pela Biblioteca Prof. Achille Bassi e Seção Técnica de Informática, ICMC/USP, com os dados fornecidos pelo(a) autor(a)

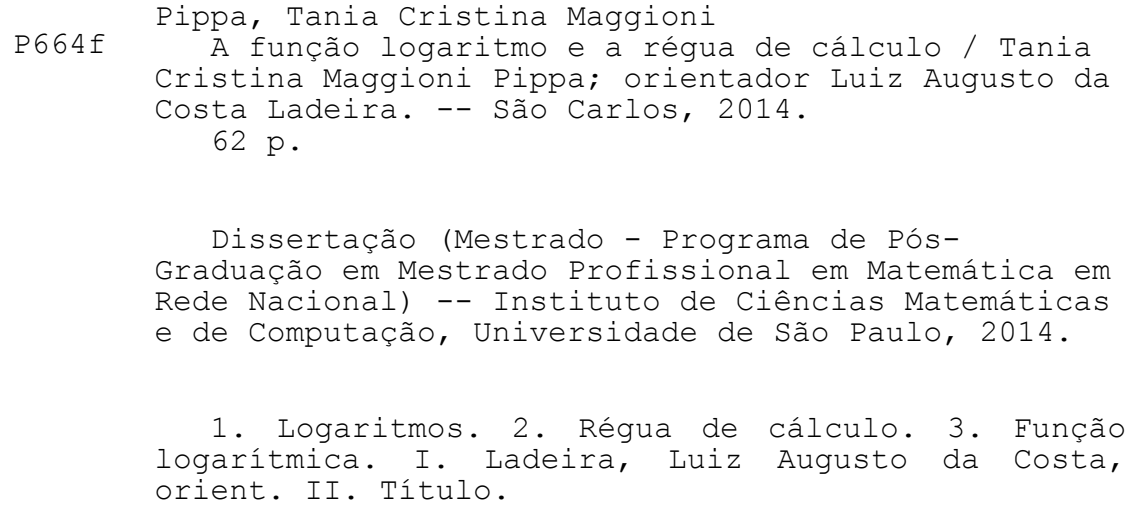




\section{DEDICATÓRIA}

Dedico este trabalho ao meu marido, companheiro e grande amor, Virgílio César Pippa, e ao meu querido filho, Lucas Maggioni Pippa, por se constituírem pessoas igualmente admiráveis, por todo incentivo e apoio nessa importante jornada. São eles estímulos que me impulsionaram a buscar vida nova a cada dia, aceitando se privarem de minha companhia pelos estudos, concedendo a mim a oportunidade de me realizar ainda mais.

Ao meu pai, Antonio Luiz Maggioni, por ser exemplo de superação nos momentos mais difíceis vivenciados por toda a minha família. 


\section{AGRADECIMENTOS}

Agradeço a Deus por conceder-me forças e entusiasmo na realização deste trabalho.

Agradeço ao meu orientador, Professor Doutor Luiz Augusto da Costa Ladeira, verdadeiro mestre, que repartiu comigo seus conhecimentos, com muita paciência e atenção, colocando em minhas mãos as ferramentas com as quais abrirei novos horizontes, rumo à satisfação plena de meus ideais profissionais e humanos.

Agradeço imensamente à Professora Doutora Ires Dias por me acompanhar de perto, orientando-me e encorajando-me a desenvolver meus estudos e meu trabalho com mais empenho.

Ao Professor Doutor Hermano de Souza Ribeiro, que compartilhou seus conhecimentos com muito entusiasmo e dedicação.

Ao Professor Doutor Miguel Vinicius Santili Frasson, que solucionou várias dúvidas minhas no campo da Informática.

Aos Professores Doutores Paulo Leandro Dattori da Silva e Sérgio Luís Zani, por tantos e belos ensinamentos.

Aos Professores Mestres Alex Carlucci Rezende e Nazar Arakelian, pela competência no esclarecimento de todas as dúvidas.

A professora Maria Lucia Yoshio, pela colaboração na realização das atividades.

À minha querida irmã Camila Fernanda Maggioni e aos meus irmãos Márcio André Maggioni e Luis Cláudio Maggioni, pelo apoio incondicional.

A todos os meus familiares, principalmente minha cunhada Maria Corina Coronatto Pippa, pelo incentivo constante. 
Agradeço também a todos os colegas do PROFMAT - Programa de Mestrado Profissional em Matemática, Alexsandra Gonçalves, Aline Cristina Lorencini de Azevedo, Bruno de Moraes Turci, Claúdia Flora Degrava, Elvis Donizeti Neves, Elisandra Regina Sampaio, Jonas Eduardo Carraschi, Joselaine Aparecida Martinez Migliato Marega, Marilaine Aparecida Rodrigues, Marcela de Freitas Souza, Mirella Kiyo Okumura, Renata Oliveira Alves Diniz, Rudney Alexandre de Lima, Sereno Ferreira, Silvana de Lourdes Galio Spolaor, Sílvia da Rocha Izidoro Ferreira, Sônia Aparecida Carreira Rufato, a qual se tornou grande amiga, e Wanderley Rodrigues de Souza, pela troca de experiências, por compartilhar desejos e ensejos, por partilhar dúvidas e sugestões e pelo enriquecimento do nosso dia-a-dia.

Aos amigos de mestrado da UFSCAR, Paulo Sérgio Adami e Priscila Paschoali Crivelenti Vilela Arantes, pela companhia e pela alegria que me proporcionaram em todas as viagens.

Aos Professores Eduardo Cabral Dias e Ana Brancato Junqueira, pela colaboração e solução de dúvidas.

Ao Thiago Roberto Zanetti, pela confecção das réguas de cálculo em cartolina para serem utilizadas em sala de aula.

Finalmente, à CAPES, pelo apoio financeiro. 
Para a elaboração efetiva do conhecimento, deve-se possibilitar o confronto entre o sujeito e o objeto, onde o educando possa penetrar no objeto, apreendê-lo em suas relações internas e externas, captar-lhe a essência. Conhecer é estabelecer relações, quanto mais abrangentes e complexas forem as relações, melhor o sujeito estará conhecendo. O educador deve colaborar com o educando na decifração, na construção da representação mental do objeto em estudo.

(Celso dos Santos Vasconcelos) 


\section{RESUMO}

PIPPA, T. C. M. A função logaritmo e a régua de cálculo. 2014, 62f. Dissertação (Mestrado - Programa de Pós-Graduação em Mestrado Profissional em Matemática em Rede Nacional) - Instituto de Ciências Matemáticas e de Computação, Universidade de São Paulo, São Carlos, 2014.

No início do século XVII, o escocês John Napier revolucionou os métodos de cálculo da época com a invenção dos logaritmos. O logaritmo de Napier não era exatamente o que usamos hoje. Naquela época, o trabalho de multiplicação, divisão, cálculo de potências e extração de raízes eram trabalhosos e feitos a partir de senos. Surgiram as primeiras tábuas de logaritmos, inventadas independentemente por John Napier (1550-1617) e Jost Bürgi (1552-1632). Pouco depois, Henry Briggs (1561-1631) aperfeiçoou essas tábuas, apresentando os logaritmos decimais. A contribuição fundamental dos logaritmos é a de facilitar os cálculos através da transformação de operações de multiplicação em adição e de operações de divisão em subtração. Essas transformações foram de grande importância nos cálculos trabalhosos que estavam envolvidos em Astronomia e Navegação. Em 1632, um matemático inglês chamado William Oughtred inventou a régua de cálculo, com base na "Tábua de Napier". Esse foi um grande passo em direção à calculadora e à construção dos computadores. Nesse trabalho propomos a utilização da régua de cálculo no ensino das propriedades dos logaritmos. Para tanto, foram estudados tópicos como a história dos logaritmos, a função logaritmo, a caracterização das funções logarítmicas, a associação de logaritmos a progressões aritméticas e geométricas e o uso de uma régua de cálculo.

Palavras-chave: logaritmos, régua de cálculo, função logarítmica. 


\begin{abstract}
PIPPA, T. C. M. A função logaritmo e a régua de cálculo. 2014, 62f. Dissertação (Mestrado - Programa de Pós-Graduação em Mestrado Profissional em Matemática em Rede Nacional) - Instituto de Ciências Matemáticas e de Computação, São Paulo, São Carlos, 2014.

In the early seventeenth century, the Scotsman John Napier revolutionized the calculation methods of that time with the invention of logarithms. The Napier logarithm was not exactly the same as we use now. At that time, the multiplication, division, exponents calculation and extracting roots were demanded extensive labor. John Napier (1550-1617) and Jost Bürgi (1552-1632) invented independently the first logarithm tables. Shortly after, Henry Briggs (1561-1631) improved these boards, presenting the decimal logarithms. The main contribution of logarithms is to make calculations easier by transforming multiplication operations into addition ones and division operations into subtraction ones. These changes have been of great importance in laborious calculations that involved Astronomy and Navigation. In 1632, an English mathematician called William Oughtred invented the slide ruler, based on the "Napier board". This was a big step towards the invention of the calculator and the computer. In this work we propose the use of the slide ruler in teaching the properties of logarithms. Thus, topics such as the history of logarithms, the logarithm function, the characterization of logarithmic functions, the association of the logarithms with arithmetical and geometrical progressions, and the use of a slide ruler were studied.
\end{abstract}

Keywords: logarithms, slide ruler, logarithmic function. 


\section{Lista de llustrações}

Esquema 1- Processo algorítmico através das barras de Napier.

Esquema 2 - Exemplo de um cálculo (47 multiplicado por 8) através das 07 barras de Napier.

Esquema 3 - Multiplicação de 1615 por 365, através das barras de Napier.

Figura 1 - Barras de Napier.

Figura 2 - Noção geométrica do logaritmo

Figura 3.1 - Uso da régua no cálculo $2 \times 3$, primeiro passo.

Figura 3.2 - Uso da régua no cálculo $2 \times 3$, segundo passo.

Figura 3.3 - Uso da régua no cálculo $2 \times 3$, terceiro passo.

Figura 3.4 - Uso da régua no cálculo $2 \times 3$, quarto passo.

Figura 4 - Uso de duas escalas no cálculo, segundo Oughtred. 36

Figura 5 - Régua na posição da multiplicação por 2.

Figura 6 - Régua na posição da multiplicação por 3.

Figura 7 - Forma atual da régua de cálculo.

Figura 8 - Forma comum de régua de cálculo.

Figura 9 - Régua de cálculo com cursor móvel

Figura 10 - Régua de cálculo em forma linear.

Figura 11 - Régua de cálculo em forma circular.

Figura 12 - Régua de cálculo em formato cilíndrico.

Figura 13 - Régua de cálculo circular utilizada na aviação.

Figura 14 - Régua de cálculo linear utilizada para avaliação de estruturas em 42 cimento, própria para canteiro de obras.

Figura 15 - Régua de cálculo circular de mesa, utilizada para avaliação de estruturas em cimento.

Figura 16 - Régua de cálculo circular de mesa, utilizada para topografia.

Gráfico 1 - Representação gráfica das funções $\mathrm{f}(\mathrm{x})=\log _{2} x$ e $g(x)=\log _{\frac{1}{2}} x$. 


\section{Lista de tabelas}

Tabela 1 - Progressão Aritmética e Progressão Geométrica 11

Tabela 2 - Números positivos e suas respectivas representações como 12 potências de 10.

Tabela 3 - Processo iterativo para cálculos de logaritmos de base $10 . \quad 18$

Tabela 4 - Escalas presentes na figura $9 . \quad 39$

Tabela 5 - Sequência de progressão aritmética e de progressão geométrica 48 calculada pelos alunos de primeira série do Ensino Médio, com 31 alunos, na E.E. Dr. Francisco da Cunha Junqueira - Bonfim Paulista - Ribeirão Preto/SP. 


\section{SUMÁRIO}

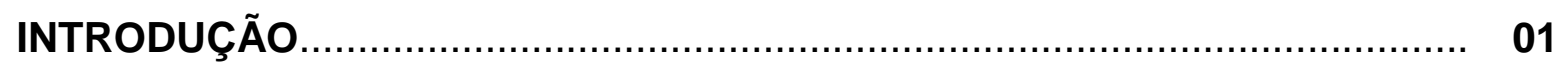

CAPÍTULO 1 - ESTUDO HISTÓRICO DOS LOGARITMOS .............................. 05

1.1 - Um breve estudo sobre as barras de Napier e as regras de

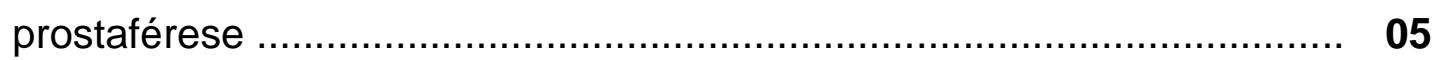

1.2 - Os fundamentos da teoria dos logaritmos.................................. 11

CAPÍTULO 2 - FUNÇÕES LOGARÍTMICAS............................................ 23

2.1 - A função logarítmica como inversa da função

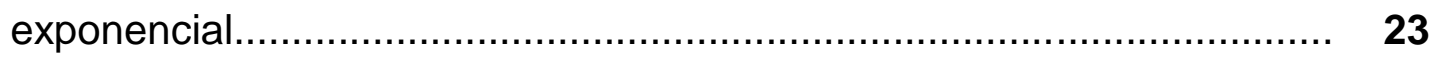

2.2 - Caracterização das Funções Logarítmicas................................... 26

2.3 - Logaritmo Natural............................................................... 28

CAPÍTULO 3 - A RÉGUA DE CÁLCULO …............................................ 33

CAPÍTULO 4 - SEQUÊNCIA DIDÁTICA PARA A UTILIZAÇÃO DA RÉGUA DE CÁLCULO EM SALA DE AULA ..................................................... 45

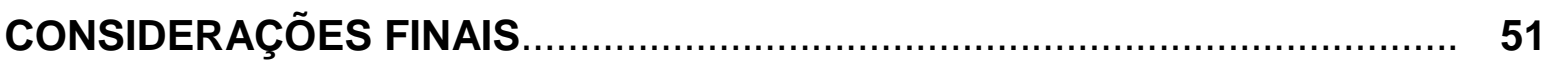

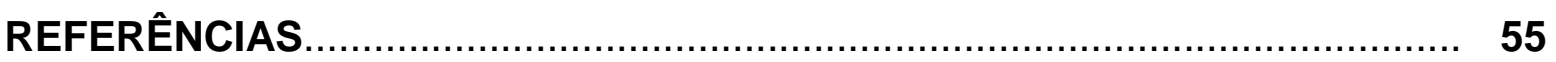




\section{INTRODUÇÃO}

A realização deste trabalho tem como finalidade estudar um tema desenvolvido na primeira série do ensino médio: os logaritmos.

Esse trabalho justifica-se pelo fato de que, quando questionada pelos alunos sobre o conceito de logaritmos, sentia que faltava o conhecimento teórico e também o conhecimento da história dos logaritmos, para responder com tranquilidade às raras perguntas dos alunos. Raras porque, no início de minha vida profissional como professora da $1^{\underline{a}}$ série do Ensino Médio, pouco estimulava os alunos a fazerem perguntas sobre o assunto, uma vez que eu mesma desconhecia a história.

Geralmente, abordava o assunto a partir da resolução da igualdade $2^{x}=3$, tendo anteriormente trabalhado com equações exponenciais. Mostrava que os valores possíveis para $x$ encontravam-se entre 1 e 2, mas que os conteúdos trabalhados até o momento em exponenciais eram insuficientes para resolver essa equação.

Ao longo da minha prática escolar, percebi que o assunto logaritmo sempre era introduzido de forma mecânica, levando à simples memorização de propriedades, não estimulando o interesse e muito menos a compreensão sobre o referido tema.

Em uma das aulas do Programa de Mestrado Profissional em Matemática (PROFMAT), durante a apresentação da Régua de Cálculo pelo professor da disciplina PMA5611 - Números e Funções Reais, decidimos pautar o nosso trabalho nesse instrumento que, apesar de subutilizado, mostra que por trás do desenvolvimento das réguas de cálculo está o aparecimento do conceito de logaritmo.

Para enfocar a régua de cálculo, resolvemos fazer uma abordagem histórica dos logaritmos até o surgimento das mesmas, para apresentar aos alunos as propriedades dos logaritmos não somente de forma mecanizada, fazendo-os decorálas sem o menor conhecimento de onde as mesmas surgiram, mas fundamentandoas através do manuseio de uma régua de cálculo. 
No Capítulo 1, tratamos do desenvolvimento algorítmico para o cálculo de produtos, conhecido como barras de Napier, e das fórmulas utilizadas pelo alemão Johannes Werner (1468-1528), conhecidas como "fórmulas de Werner".

Salientamos, nesse capítulo, que o nobre escocês Lord John Napier nasceu em 1550 e era um homem excêntrico e tenaz. Ele inventou uma ferramenta de grande utilidade na Matemática. A ideia de John Napier veio trazer uma importante ajuda para os campos da Astronomia, da Cartografia, da Navegação e até mesmo da Astrologia. Para a criação dos logaritmos, Napier buscou inspiração em determinadas relações da Trigonometria, observando relações interessantes entre os expoentes dos termos de progressões aritméticas e geométricas. O grande astrônomo alemão Kepler também desenvolveu interesse pelos logaritmos de Napier utilizando-os para recalcular a órbita do planeta Marte com maior precisão.

O renomado professor inglês de Geometria, Henry Briggs, nasceu em 1561 e foi o responsável por aperfeiçoar e divulgar a criação de Napier. O professor Briggs era um estudioso, competente e reconhecido na Europa. Seu entusiasmo pelos logaritmos levou-o a escrever para o Lord Napier pedindo que o recebesse para uma conversa em seu castelo na Escócia. O Lord Napier concordou imediatamente. A viagem de Briggs ao castelo no Napier se deu em 1615. No encontro, Napier e Briggs decidiram qual é a base mais conveniente para o trabalho com os logaritmos, e definiram o logaritmo de 1 como sendo zero e o logaritmo de 10 como sendo 1.

Nesse capítulo, além dos logaritmos decimais, destacamos os logaritmos naturais, que desempenham um papel relevante em Matemática; a base do logaritmo natural é o número irracional e, dado aproximadamente por 2,718...

No Capítulo 2, o trabalho consiste na apresentação da função logarítmica como inversa da exponencial e na caracterização das funções logarítmicas, a partir da propriedade de transformar produtos em somas. As funções logarítmica e exponencial desempenham um papel importante na descrição de fenômenos de evolução e na análise matemática. Apresentamos o logaritmo natural, definindo a função logaritmo natural por meio de uma integral.

No Capítulo 3, tratamos da régua de cálculo. Quanto às réguas de cálculos, vamos observar que são instrumentos que não fornecem valores exatos, mas aproximados. Em geral, as réguas de cálculos são utilizadas para realizar operações de multiplicação e divisão, pois as tarefas de multiplicar e dividir são transformadas 
em soma e subtração, respectivamente, baseando nas seguintes propriedades matemáticas

$$
\begin{gathered}
\log (x \cdot y)=\log x+\log y \\
\mathrm{e} \\
\log \left(\frac{x}{y}\right)=\log x-\log y .
\end{gathered}
$$

No Capítulo 4, apresentamos uma sequência didática, considerando o potencial pedagógico para a utilização da régua de cálculo em sala de aula, ilustrando as propriedades operatórias dos logaritmos descritas acima. 


\section{CAPÍTULO 1}

\section{ESTUDO HISTÓRICO DOS LOGARITMOS}

As necessidades de cada época estimulam a criação de teorias e de ferramentas para solucionar problemas. Assim aconteceu com os logaritmos, que foram criados quando os cálculos numéricos passaram a ser um obstáculo na evolução das ciências (PAIVA, 2010).

Eves (2004, p. 341), salienta que quatro notáveis invenções vieram atender sucessivamente às demandas crescentes de tornar cada vez mais rápidos e precisos os cálculos numéricos: a notação indo-arábica, as frações decimais, os logaritmos e os modernos computadores, sendo os logaritmos, inventados por John Napier, no início do século XVII, considerados grandes poupadores de trabalho, pois transformam uma multiplicação em adição e uma divisão em subtração, facilitando o trabalho com números exageradamente grandes ou números muito pequenos.

Segundo Eves (2004, p.341-342)

John Napier (1550-1617), que nasceu quando seu pai tinha apenas dezesseis anos de idade, viveu a maior parte de sua vida na majestosa propriedade de sua família, o castelo de Murchiston, perto de Edimburgo, Escócia.

John Napier não era um matemático profissional; ele dedicava-se à matemática e ciência, por diletantismo,

resultando daí que quatro produtos de seu gênio tenham entrado para a história da matemática: (1) a invenção dos logaritmos; (2) o engenhoso dispositivo mnemônico conhecido como regra das partes circulares, para reproduzir fórmulas usadas na resolução de triângulos esféricos; (3) pelo menos duas fórmulas trigonométricas de um grupo de quatro conhecidas como analogias de Napier, úteis na resolução de triângulos esféricos obliquângulos; (4) a invenção de um instrumento conhecido como barras de Napier ou ossos de Napier (Figura 1), bastões usados para efetuar mecanicamente 
multiplicações, divisões e extrair raízes quadradas de números. (EVES, 2004, p. 342).

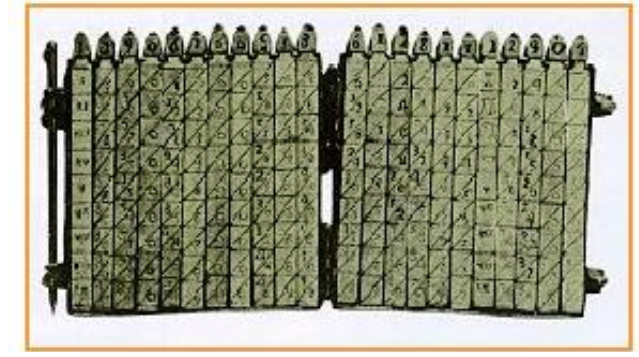

Figura 1 - Barras de Napier.

Fonte: Souza, $2010^{1}$.

\section{1 - Um breve estudo sobre as barras de Napier e as regras de prostaférese}

Preocupado com os cálculos maiores e de difícil compreensão, Napier desenvolveu um processo algorítmico para o cálculo de produtos - barras de madeira conhecidas por "ossos de Napier", que eram tabelas de multiplicação gravadas em bastão, o que evitava a memorização da tabuada.

Pode-se perceber que Napier possibilitou, através de sua invenção, sanar as grandes dificuldades encontradas nas experiências sem sucesso dos cálculos matemáticos em multiplicação (Esquema 1). Assim, a invenção da barra de Napier, ou ossos de Napier, descrita em seu trabalho Rabdologiae, publicado em 1617, conseguiu alcançar muita fama.

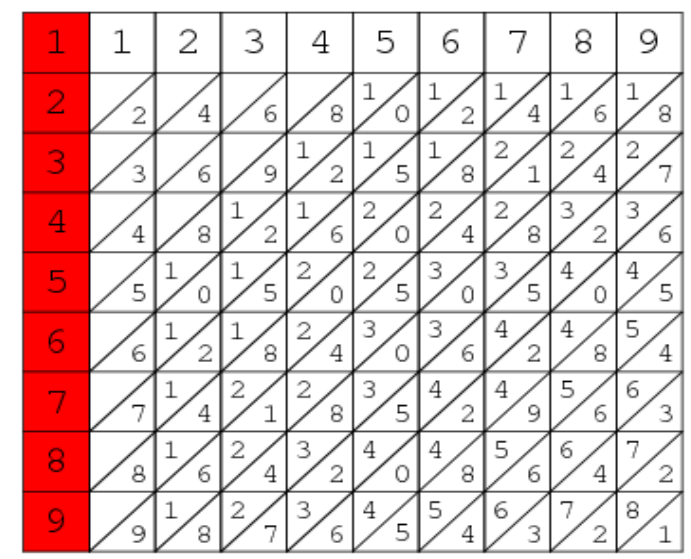

Esquema 1- Processo algorítmico através das barras de Napier.

Fonte: Site Fatos Matemáticos ${ }^{2}$.

\footnotetext{
${ }^{1}$ Disponível em: <http://fernandoloppes.blogspot.com.br/2011/11/barras-de-napier.html>. Acesso em 12 jul. 2013.
} 
Conforme a figura acima, suponha que queiramos multiplicar 47 por 8 . Colocamos primeiramente as barras dirigidas por 4 e por 7 lado a lado (Esquema 2). Em seguida, identificamos a oitava linha que corresponde ao multiplicador 8. Nessa linha, localizamos os valores que devem ser somados de acordo com cada casa decimal. Desse modo, obtemos o resultado da multiplicação 47 × $8=300+50+20+$ $6=376$ ou podemos calcular $47 \times 8=300+70+6=376$ :

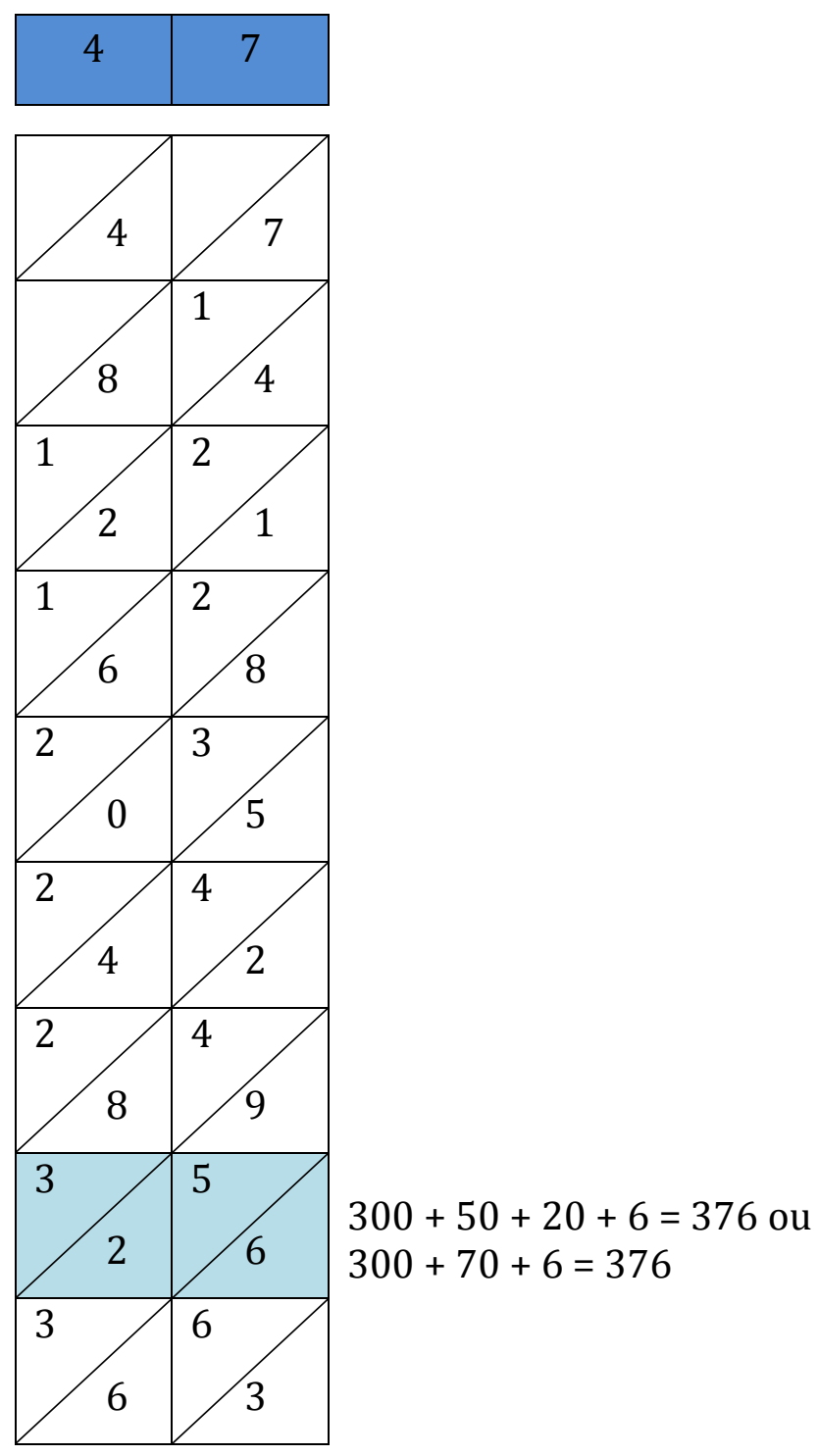

Esquema 2 - Exemplo de um cálculo (47 multiplicado por 8) através das barras de Napier.

${ }^{2}$ Disponível em: <http://fatosmatematicos.blogspot.com.br/2009/10/as-barras-de-napier.html>. Acesso em 12 jul. 2013. 
Para melhor compreender a barra de Napier, atente-se ao exemplo demonstrado por Eves (2004, p. 369), retirado do excerto do livro de Napier (1617), o qual menciona a multiplicação de 1615 por 365. Esse processo, descrito no esquema 3, ocorre com a ajuda de tiras de ossos, metais, madeira ou cartão, previamente preparadas. Para cada um dos dez dígitos, devem-se ter tiras para os vários múltiplos de determinado número. Nesse exemplo, ilustrado no esquema 3 , observa-se o destaque para o número 6 e a possibilidade de ilustrar os múltiplos desse dígito. Eves (2004) explica que deveria se colocar lado a lado as tiras, encabeçando-as por $1,6,1,5$. Os resultados da multiplicação do dígito 6 pelo número 365, ou seja, respectivamente pelos dígitos $3,6,5$, do qual se obteve 4845 , 9690 e 8075 podem ser facilmente lidos, sendo necessário, no máximo, efetuar algumas adições simples de dois dígitos na diagonal. Após a realização de cada multiplicação individual, há a necessidade de apenas somar os resultados parciais, respeitando a ordem decimal de cada um deles, para se obter o resultado final.
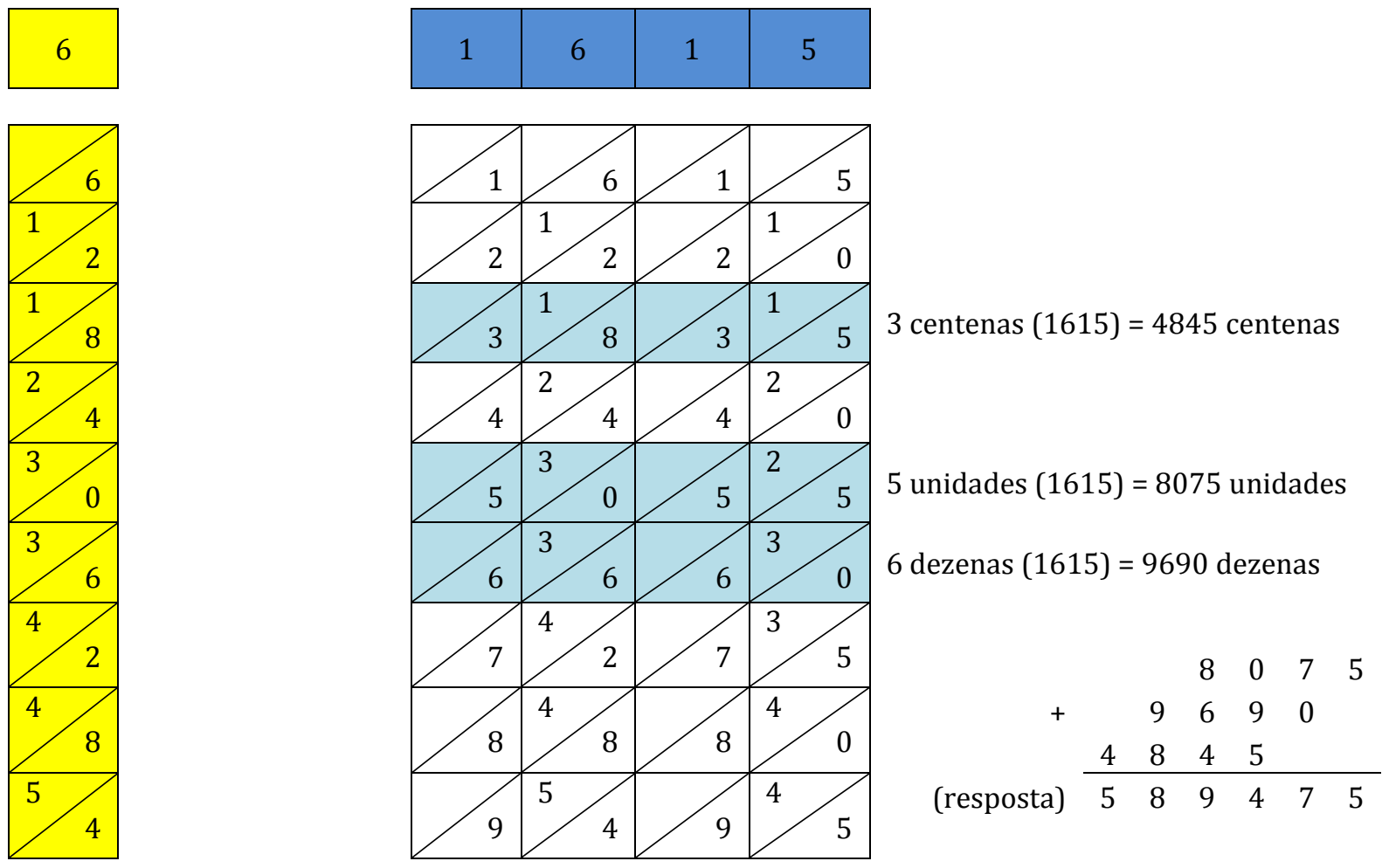

Esquema 3 - Multiplicação de 1615 por 365, através das barras de Napier ${ }^{3}$.

\footnotetext{
${ }^{3}$ Retirado de Eves (2004, p. 370).
} 
No início do século XVII, John Napier revelou sua invenção dos logaritmos, destacando-os como instrumentos de cálculo com o poder de reduzir multiplicações e divisões a simples operações de adição e subtração.

A fórmula trigonométrica $2 \cos \mathrm{A} \cos \mathrm{B}=\cos (\mathrm{A}+\mathrm{B})+\cos (\mathrm{A}-\mathrm{B})$, bastante conhecida na geração de Napier, constitui a ideia antecessora aos cálculos logarítmicos de Napier. Para se compreender melhor, entende-se que se têm dois números $\cos (\mathrm{A}+\mathrm{B})+\cos (\mathrm{A}-\mathrm{B})$ podendo estender o conceito dessa fórmula para a conversão do produto de dois outros números quaisquer somados a mais dois números.

Como exemplo, Eves (2004, p. 343), utilizou a fórmula para achar o produto de 437,64 por 27,327, com tábua de cossenos, na perspectiva de achar a interpolação, se necessário, nos ângulos $\mathrm{A}$ e $\mathrm{B}$, de forma que: $\cos A=\frac{0,43764}{2}=$ 0,21882 e $\cos B=0,27327$.

Dessa forma, ao utilizar a tábua de cossenos, foi preciso encontrar os cossenos da soma e da diferença dos tais números citados anteriormente e somálos, obtendo o produto de 0,43764 e 0,27327, ajustando a vírgula do número decimal e, com isso, compreendendo que a procura do produto foi reduzido à condição de uma simples adição. Eves (2004, p. 343) também demonstra que houve outras três fórmulas utilizadas pelo alemão Johannes Werner (1468-1528), que simplificou cálculos de comprimentos em astronomia e matemática, ainda no final do século XVII, com intuito para converter produtos em somas e diferenças. Essas fórmulas são: $2 \operatorname{sen} A \cos B=\operatorname{sen}(A+B)+\operatorname{sen}(A-B) ; 2 \cos A \operatorname{sen} B=\operatorname{sen}(A+B)-\operatorname{sen}(A-B) ; 2$ $\operatorname{sen} A \operatorname{sen} B=\cos (A-B)-\cos (A+B)$. Ressaltando que essas fórmulas são utilizadas para simplificar o produto em somas e subtrações.

As regras acima parecem ter sido usadas por Werner para simplificar os cálculos astronômicos, pois há indícios que em uma das viagens de James VI, da Escócia, em 1590, à Dinamarca, John Napier tomou conhecimento do maravilhoso artifício da prostaférese, muito usado em computações nos observatórios, sendo encorajado a redobrar seus esforços e finalmente publicar, em 1614, o Mirifici logarithmorum canonis descriptio (Uma descrição da maravilhosa regra dos logaritmos).

Na segunda metade do século XVI, a Dinamarca tornou-se um centro cultural, que se preocupava com os problemas relacionados com a navegação e com os 
cálculos exageradamente grandes. Para facilitar o trabalho com esses cálculos, observamos em Boyer (2010, p. 211) o uso de um método para abreviá-los. Como se pode observar abaixo:

$$
\begin{aligned}
& \operatorname{sen}(A+B)=\operatorname{sen} A \cdot \cos B+\operatorname{sen} B \cdot \cos A \\
& \operatorname{sen}(A-B)=\operatorname{sen} A \cdot \cos B-\operatorname{sen} B \cdot \cos A
\end{aligned}
$$

Somando-se as duas expressões (1 e 2):

$$
\operatorname{sen}(A+B)+\operatorname{sen}(A-B)=
$$

$\operatorname{sen} A \cdot \cos B+\operatorname{sen} B \cdot \cos A+\operatorname{sen} A \cdot \cos B-\operatorname{sen} B \cdot \cos A \cdot$

$$
\begin{gathered}
\operatorname{sen}(A+B)+\operatorname{sen}(A-B)= \\
2 \operatorname{sen} A \cdot \cos B
\end{gathered}
$$

\section{ou}

$\operatorname{sen} A \cdot \cos B=\frac{1}{2} \operatorname{sen}(A+B)+\frac{1}{2} \operatorname{sen}(A-B)=\frac{1}{2}[\operatorname{sen}(A+B)+\operatorname{sen}(A-B)]$

Por exemplo, utilizando o método acima para efetuar o produto entre $0,34202 \times 0,97437$, tem-se:

Consultando a tabela trigonométrica:

$\operatorname{sen} 20^{\circ}=0,34202$

$\cos 13^{\circ}=0,97437$

A fórmula afirma que:

$$
\operatorname{sen} 20^{\circ} \cdot \cos 13^{\circ}=\frac{1}{2}\left(\operatorname{sen} 33^{\circ}+\operatorname{sen} 7^{\circ}\right)
$$


As tábuas informam que:

$\operatorname{sen} 33^{\circ}=0,54464$,

$\operatorname{sen} 7^{\circ}=0,12187$,

$\operatorname{sen} 33^{\circ}+\operatorname{sen} 7^{\circ}=0,66651$,

$$
\frac{1}{2}\left(\operatorname{sen} 20^{\circ}+\operatorname{sen} 13^{\circ}\right)=0,333255
$$

Assim, com aproximação a menos de um décimo de milésimo, podemos escrever: $\operatorname{sen} 20^{\circ} \cdot \cos 13^{\circ}=0,34202 \times 0,97437=0,33325407$, aproximadamente 0,33325 .

\section{2 - Os fundamentos da teoria dos logaritmos}

Por volta de 1590, Napier mostrou ter grande conhecimento da correspondência entre progressões aritméticas (PA) e geométricas (PG). Ele observou que o produto ou divisão de dois termos da PG estava associado à soma ou diferença dos respectivos termos da PA. Partindo dessa correspondência, criou os logaritmos.

Para uma maior compreensão pode-se tomar, por exemplo, duas progressões, uma aritmética e uma geométrica:

Tabela 1 - Progressão Aritmética e Progressão Geométrica

\begin{tabular}{llllllllll}
\hline Aritmética: & 0 & 1 & 2 & 3 & 4 & 5 & 6 & 7 & $8 \ldots$ \\
\hline Geométrica: & 1 & 2 & 4 & 8 & 16 & 32 & 64 & 128 & $256 \ldots$ \\
\hline
\end{tabular}

Com base nessas duas progressões, considere que os termos da progressão aritmética correspondem aos expoentes de potências de base 2, e os termos da progressão geométrica correspondem aos resultados das operações indicadas. Desse modo, a progressão geométrica pode ser representada por $2^{0}=1,2^{1}=2,2^{2}=4$, $2^{3}=8,2^{4}=16$ e assim por diante. Para determinar o produto $2^{2} \times 2^{3}$, basta somar os expoentes, obtendo $2^{2+3}=2^{5}$. Diante disso, para se calcular o produto, conserva-se a 
base e somam-se os números de seus expoentes, resultando no produto desejado. Assim: $2^{2+4}=2^{6}$, como o resultado do sétimo termo da progressão geométrica, igual a 64, e para obter-se o restante da progressão basta seguir o raciocínio de elevar a base 2 a cada número indicado na relação aritmética, isto é, basta elevar a base 2 aos expoentes $0,1,2,3,4,5,6,7,8, \ldots$ Observa-se que essas ideias aplicam-se igualmente a uma progressão geométrica qualquer: $1, a^{2}, a^{3}, a^{4}, a^{5}, \ldots$

A ideia de Napier, segundo Paiva (2010), é relativamente simples: representam-se os números positivos como potências de um mesmo número. Por exemplo, cada coluna da tabela abaixo (Tabela 2) apresenta um número e a respectiva representação como potência de base 10 . Assim, na primeira coluna da tabela, tem-se $1,78090=10^{0,25064}$.

Tabela 2 - Números positivos e suas respectivas representações como potências de 10.

\begin{tabular}{ccccc}
\hline Número & 1,78090 & 1,82881 & 3,25694 & 5,80029 \\
\hline Potência de base 10 & $10^{0,25064}$ & $10^{0,26217}$ & $10^{0,51281}$ & $10^{0,76345}$ \\
\hline
\end{tabular}

Por um lado, pode-se calcular com essa tabela:

$3,25694 \cdot 1,78090=10^{0,51281} \cdot 10^{0,25064}=10^{0,51281+0,25064}=10^{0,76345}=5,80029$.

Observa-se em (3) que o produto foi calculado pela soma dos expoentes das potências de dez. Por outro lado, também calcula-se com a Tabela 2:

$3,25694: 1,78090=10^{0,51281}: 10^{0,25064}=10^{0,51281-0,25064}=10^{0,26217}=1,82881$.

Observa-se em (4) que o quociente foi calculado pela diferença dos expoentes das potências de dez.

Denominando 10 como base, cada termo da progressão aritmética é então o logaritmo do termo correspondente na progressão geométrica. Generalizando a progressão geométrica tem-se: 


$$
b, b^{2}, b^{3}, b^{4}, b^{5}, b^{6}, \ldots, b^{m}, \ldots, b^{n}, \ldots
$$

Pode-se associar cada termo da progressão geométrica acima com os termos da progressão aritmética seguinte:

$$
1,2,3,4,5,6, \ldots, m, \ldots, n, \ldots
$$

Daí tem-se que o produto $b^{m} \cdot b^{n}=b^{m+n}$ de dois termos da primeira progressão está associado à soma $m+n$ dos termos correspondentes da segunda progressão. Napier escolheu o número $b$ bem próximo de 1, para manter os termos da progressão geométrica suficientemente próximos de maneira que se possa usar interpolação para preencher as lacunas entre os termos na correspondência precedente (EVES, 2004, p. 344). Com essa finalidade, Napier tomou para $b$ o valor $1-\frac{1}{10^{7}}=0,9999999$. Com o intuito de evitar decimais, ele multiplicou cada potência por $10^{7}$. Assim:

$$
\begin{aligned}
& 0,9999999 \cdot 10^{7}=\frac{9}{10} \cdot 10^{7}+\frac{9}{100} \cdot 10^{7}+\frac{9}{1000} \cdot 10^{7}+\ldots+\frac{9}{10000000} \cdot 10^{7}= \\
& =9 \cdot\left(10^{6}+10^{5}+10^{4}+10^{3}+10^{2}+10^{1}+10^{0}\right)= \\
& =9 \cdot\left[\frac{10^{0}\left(1-10^{7}\right)}{1-10}\right]=9 \cdot\left(\frac{1-10^{7}}{-9}\right)=-1+10^{7}=10^{7}-1=9999999 .
\end{aligned}
$$

Colocando $10^{7}$ em evidência, tem-se:

$$
\begin{aligned}
0,9999999 \cdot 10^{7} & =\frac{9}{10} \cdot 10^{7}+\frac{9}{100} \cdot 10^{7}+\frac{9}{1000} \cdot 10^{7}+\ldots+\frac{9}{10000000} \cdot 10^{7}= \\
& =10^{7}\left(\frac{9}{10}+\frac{9}{100}+\frac{9}{1000}+\ldots+\frac{9}{10000000}\right)= \\
& =10^{7}(0,9+0,09+0,009+\cdots+0,0000009)=
\end{aligned}
$$




$$
\begin{gathered}
=10^{7}\left\{\frac{0,9\left[1-(0,1)^{7}\right]}{1-0,1}\right\}= \\
=10^{7}\left\{\frac{0,9\left[1-(0,1)^{7}\right]}{0,9}\right\}= \\
=10^{7}\left[1-10^{-7}\right]= \\
=10^{7}\left[1-\frac{1}{10^{7}}\right] .
\end{gathered}
$$

Então, tomando $N=10^{7} \cdot\left[1-\frac{1}{10^{7}}\right]^{L}$, Napier chamou $L$ de "logaritmo" do número N. Segue-se que o logaritmo de Napier de $10^{7}$ é 0 e o de $10^{7} \cdot\left(1-\frac{1}{10^{7}}\right)=$ 9999999 é 1.

Deve-se ter em mente que Napier não trabalhava com o conceito de "base" de um sistema de logaritmos. Para demonstrar isso suponha, por absurdo, que b é essa base. Então:

$$
\begin{gathered}
N \log _{b} 10^{7}=0 \rightarrow b^{0}=10^{7} \\
N \log _{b} 10^{7} \cdot\left(1-\frac{1}{10^{7}}\right)=1 \rightarrow b^{1}=b=10^{7} \cdot\left(1-\frac{1}{10^{7}}\right) \\
N \log _{b} 10^{7} \cdot\left(1-\frac{1}{10^{7}}\right)^{2}=2 \rightarrow b^{2}=10^{7} \cdot\left(1-\frac{1}{10^{7}}\right)^{2} \Rightarrow b=10^{\frac{7}{2}} \cdot\left(1-\frac{1}{10^{7}}\right)
\end{gathered}
$$

Pode-se modificar o sistema original de Napier, dividindo $\mathrm{N}$ e $L$ por $10^{7}$. Desse modo, escreve-se:

$$
\begin{gathered}
\log _{b} 1=0 \rightarrow b^{0}=1 \\
\log _{b}\left(1-\frac{1}{10^{7}}\right)=\frac{1}{10^{7}} \rightarrow b^{0,0000001}=\left(1-\frac{1}{10^{7}}\right) \rightarrow b=\left(1-\frac{1}{10^{7}}\right)^{\frac{1}{0,0000001}} \rightarrow
\end{gathered}
$$




$$
\rightarrow b=\left(1-\frac{1}{10^{7}}\right)^{\frac{2}{0,0000002}} \rightarrow b=\left(1-\frac{1}{10^{7}}\right)^{10000000}
$$

Esse novo sistema de logaritmos passa a ter uma base única e definida $\left(1-\frac{1}{10^{7}}\right)^{10000000}=\left(1-\frac{1}{10^{7}}\right)^{10^{7}}$. Esse número é 0 inverso do número $e=2,718281829 \ldots$, o qual é a base dos logaritmos naturais ou limite fundamental.

Logo, se encontra um sistema de logaritmos na base 1/e, pois

$$
\left(1-\frac{1}{10^{7}}\right)^{10^{7}} \cong \lim _{n \rightarrow \infty}\left(1-\frac{1}{n}\right)^{n}=\frac{1}{e}
$$

Napier, que dedicou pelo menos vinte anos a essa teoria, explicou essa noção geometricamente do seguinte modo: Considere um segmento de reta $\mathrm{AB}$ e uma semirreta DE, de origem D, conforme ilustra a Figura 2.

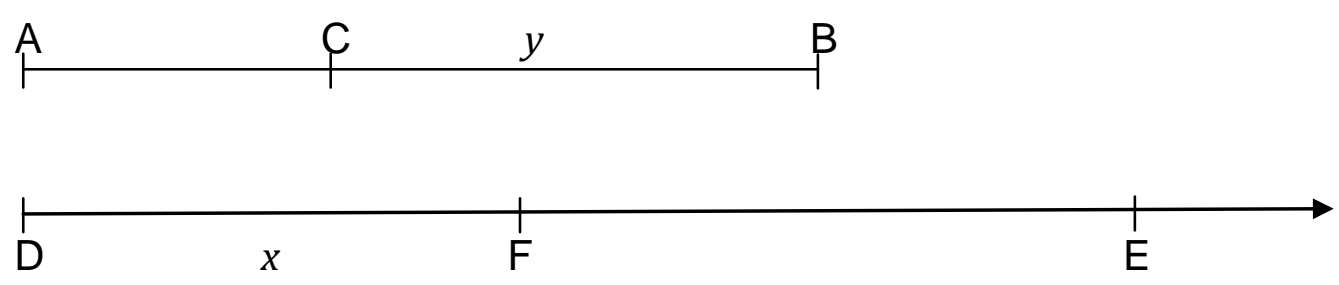

Figura 2 - Noção geométrica do logaritmo. Fonte: Eves, 2004, p. 344.

Suponha que os pontos $\mathrm{C}$ e $\mathrm{F}$ se coloquem em movimento simultaneamente a partir de A e D, com a mesma velocidade inicial. Porém, admita que C movimenta-se em uma velocidade numérica igual à distância $\mathrm{CB}$ e que $\mathrm{F}$ esteja se locomovendo com velocidade uniforme. Napier, segundo Eves (2004 p. 344-345), definiu DF como o logaritmo de $\mathrm{CB}$. Isto é, colocou $\mathrm{DF}=x$ e $\mathrm{CB}=y$, nomeando de Napier-logaritmo de $y$, ou seja, Nap $\log y$. Considerou o segmento AB como potência de $10^{7}$, evitando, com isso, o resultado com frações. Explicando que na época as melhores tábuas de senos eram dispostas com cerca de sete casas decimais. 
Dessa forma, a partir da experiência de Napier, tem-se $A B=10^{7}$ e se $A B=10^{7}$ pode-se considerar $\mathrm{AC}=10^{7}-y$. Como $\mathrm{C}$ desloca-se com velocidade igual à distância $\mathrm{CB}$, temos $\frac{-d y}{d t}=y$. Segue-se que $\frac{d y}{y}=-d t$.

Integrando-se, obtemos:

$$
\ln y=-t+k
$$

Para obter a constante de integração, notemos que $y=10^{7}$ quando $t=0$, portanto $k=\ln 10^{7}$. Assim

$$
\ln y=-t+\ln 10^{7}
$$

Portanto

$$
t=\ln 10^{7}-\ln y=\ln \frac{10^{7}}{y}
$$

Por outro lado, como a velocidade de F é constante, dada por $\frac{x}{d t}=10^{7}$ e $x=0$ quando $t=0$, tem-se

$$
x=10^{7} t
$$

Combinando (5) e (6), tem-se:

$$
\text { Nap } \log y=x=10^{7} t=10^{7} \ln \left(\frac{10^{7}}{y}\right) .
$$

Usando a igualdade $\log _{a} \frac{1}{w}=\log _{\frac{1}{a}} w$, tem-se:

$$
\text { Nap } \log y=10^{7} \log _{\frac{1}{e}}\left(\frac{y}{10^{7}}\right)
$$


Segundo Eves (2004, p. 345),

a afirmação feita frequentemente de que os logaritmos neperianos são logaritmos naturais não correspondem de fato à verdade. Observe que os logaritmos neperianos decrescem conforme os números crescem, ao contrário do que ocorre com os logaritmos naturais.

Nota-se ademais que, sobre uma sucessão de períodos de tempos iguais, y decresce em progressão geométrica enquanto $x$ cresce em progressão aritmética. Assim verifica-se o princípio fundamental de um sistema de logaritmos, a associação de uma progressão geométrica a uma aritmética. Daí que, por exemplo, se $a / b=c / d$, então:

$$
\text { Nap log } a-N a p \log b=\text { Nap } \log c-N a p \log d
$$

que é um dos muito resultados estabelecidos por Napier.

Essa teoria, publicada no texto Mirifici logatithmorum canonis descriptio (Descrição da Maravilhosa Lei dos Logaritmos) em 1614, despertou um vasto interesse. Tanto que, no ano seguinte à sua publicação, Henry Briggs (1561-1631), professor de geometria em Oxford e também grande admirador de Napier e dessa teoria, viajou em 1615 até Edimburgo, Escócia, para externar o seu reconhecimento ao grande inventor dos logaritmos. Durante essa visita, Napier e Briggs discutiram possíveis modificações no método dos logaritmos,

concordando que as tábuas de logaritmos seriam mais úteis se fossem alteradas de modo que o logaritmo de 1 fosse 0 e o logaritmo de 10 fosse igual a um, nascendo assim os logaritmos briggsianos ou comuns, os logaritmos dos dias de hoje. Esses logaritmos, que são essencialmente os logaritmos de base 10 , devem sua superioridade em cálculos numéricos ao fato de que nosso sistema de numeração é decimal. (EVES, 2004, p. 235).

Briggs, desse modo, construiu uma tábua de logaritmos na base 10, começando por $\log 10=1$ e, depois, encontrou outros logaritmos tomando raízes sucessivas.

Assim, sendo $\sqrt{10}=3,162277$, Briggs tinha que $\log 3,162277=0,500000$ e, sendo $10^{\frac{3}{4}}=\sqrt{31,62277}=5,623413$, tinha que $\log 5,623413=0,7500000$. Seguindo nesse processo, Briggs calculou outros logaritmos comuns.

Abaixo, com base na Tabela 3, descreve-se um processo iterativo para calcular logaritmos na base 10 . 
Tabela 3 - Processo iterativo para cálculos de logaritmos de base 10.

\begin{tabular}{llr}
\hline $10^{1 / 2}=3,16227766$ & $10^{1 / 32}=1,074607828$ & $10^{1 / 512}=1,004507364$ \\
$10^{1 / 4}=1,77827941$ & $10^{1 / 64}=1,036632928$ & $10^{1 / 1024}=1,002251148$ \\
$10^{1 / 8}=1,333521432$ & $10^{1 / 128}=1,018151722$ & $10^{1 / 2048}=1,001124941$ \\
$10^{1 / 16}=1,154781985$ & $10^{1 / 256}=1,009035045$ & $10^{1 / 4096}=1,000562313$ \\
\hline
\end{tabular}

Em primeiro lugar, observa-se que a igualdade $\log y=x$ significa que $y=10^{x}$. Desse modo, se o maior número da Tabela 3 que não excede $y$ é $10^{1 / n}$, então escreve-se que $y=10^{1 / n} b$, com $b<y$, tomando $1 / n$ como uma aproximação, por falta, de $\log y$.

A partir da Tabela 3 calcula-se, como exemplo, $\log 2$. Vê-se na tabela que $10^{1 / 4}$ é o maior número que não excede 2 : toma-se então $1 / 4$ como primeira aproximação de $\log 2$, ou seja,

$$
\log 2 \approx 0,25 \text {. }
$$

Dividindo 2 por $10^{1 / 4}$ obtém-se o quociente $x_{1}=1,12468265$, de modo que $2=$ $10^{1 / 4} X_{1}$

Agora, pode-se repetir o procedimento acima com $x_{1}$, no lugar de 2 . O maior número da tabela acima que não excede $x_{1}$ é $10^{1 / 32}$. Assim, escreve-se

$$
2=10^{1 / 4} x_{1}=10^{1 / 4} 10^{1 / 32} x_{2}
$$

em que $x_{2}=1,04659823$ é o quociente de $x_{1}$ por $10^{1 / 32}$.

Toma-se então o número $1 / 4+1 / 32=0,25+0,03125=0,28125$ como uma segunda aproximação de $\log 2$, ou seja,

$\log 2 \approx 0,28125$.

Agora, nota-se que $10^{1 / 64}$ é o maior número da tabela que é menor do que $x_{2}$. denotando por $x_{3}=1,00961314$ o quociente de $x_{2}$ por $10^{1 / 64}$, pode-se escrever

$$
2=10^{1 / 4} 10^{1 / 32} 10^{1 / 64} x_{3}
$$


Essa é a terceira aproximação de $\log 2$ é $1 / 4+1 / 32+1 / 64=0,296875$, isto é,

$\log 2 \approx 0,296875$

Dividindo $x_{3}$ por $10^{1 / 256}$, que é o maior número da tabela acima que não excede $x_{3}$, obtém-se o quociente $x_{4} \approx 1,00057292$.

Assim, $2=10^{1 / 4} 10^{1 / 32} 10^{1 / 64} 10^{1 / 256} x_{4}$ : a quarta aproximação de $\log 2$ é $1 / 4+1 / 32+1 / 64+1 / 256=0,25+0,03125+0,015625+0,00390625=0,30078125$, ou seja,

$\log 2 \approx 0,30078125$

Finalmente, repetindo o procedimento com $x_{4}$ no lugar de $x_{3}$, pode-se escrever

$$
2=10^{1 / 4} 10^{1 / 32} 10^{1 / 64} 10^{1 / 256} 10^{1 / 4096} x_{5}\left(\operatorname{com} x_{5} \approx 1,0000106\right)
$$

e tem-se

$$
\log 2 \approx 1 / 4+1 / 32+1 / 64+1 / 256+1 / 4096=0,301025
$$

Agora, pode-se enunciar o procedimento geral para calcular o logaritmo de um número $x$. Seja $10^{1 / n_{1}}$ o maior número da Tabela 3 que não excede $x$, toma-se $1 / n_{1}$ como primeira aproximação de $\log x$. Se $x_{1}$ denota o quociente de $x$ por $10^{1 / n_{1}}$, pode-se escrever $x=10^{1 / n_{1}} x_{1}$.

Agora, repetindo esse procedimento $\operatorname{com} x_{1}$ no lugar de $x$ : Se $10^{1 / n_{2}}$ é o maior número da tabela que não excede $x_{1}$, e $x_{2}$ é o quociente de $x_{1}$ por $10^{1 / n_{2}}$, pode-se escrever $x=10^{1 / n_{1}} 10^{1 / n_{2}} x_{2}$, e toma-se $1 / n_{1}+1 / n_{2}$ como segunda aproximação de $\log x$. Continuando deste modo, escreve-se

$$
x=10^{1 / n_{1}} 10^{1 / n_{2}} \ldots 10^{\frac{1}{n_{k}}} x_{k} \text { e } 1 / n_{1}+1 / n_{2}+\ldots+1 / n_{k}
$$

que é a aproximação de $\log x$. O processo é interrompido quando se atinge a aproximação desejada para $\log x$. 
Parece, até agora, que a invenção dos logaritmos foi obra somente de John Napier. Entretanto, o suíço Jobst Bürgi (1552-1632), fabricante de instrumentos para astronomia, matemático e inventor, concebeu e construiu uma tábua de logaritmos independente de Napier. Bürgi, paralelamente a Napier, desenvolveu ideias semelhantes sobre logaritmos, as quais foram publicadas somente em 1620, seis anos após Napier publicar a Descriptio. Acredita-se que Napier teve a ideia de logaritmos antes de Bürgi, porém Napier trabalhou com uma abordagem geométrica, enquanto Bürgi descreveu uma abordagem algébrica de logaritmos. Ao invés de partir de um número pouco menor que um (1-10-7, utilizado por Napier), Jobst Bürgi escolheu um número um pouco maior que um, o número $1+10^{-4}$, multiplicando as potências desse número por $10^{8}$ e não por $10^{7}$ como fez Napier.

Os logaritmos foram adotados por toda a Europa. Na astronomia, em particular, Laplace afirmou que, com a invenção dos logaritmos, "ao diminuir o trabalho, dobrou a vida dos astrônomos" (EVES, 2004, p. 346). Na Itália, os logaritmos foram introduzidos por Bonaventura Cavalieri; já na Alemanha, foram introduzidos por Johann Kepler. Edmund Wingate realizou o mesmo trabalho na França.

O vocábulo logarithmus foi criado por Napier pela junção das palavras gregas: logos, que significa razão ou cálculo, e arithmós, que significa número. Compreendese que o logaritmo é uma operação matemática bem como a soma, a subtração, a multiplicação e divisão.

Atualmente, um logaritmo é considerado universalmente como um expoente, isto é, um expoente que uma determinada base deve ter para produzir certa potência. Por exemplo, na notação $a=b^{x}$ é dito que $x$ é o logaritmo de $a$ na base $b$. A partir dessa definição, as leis dos logaritmos decorrem imediatamente das leis dos expoentes, apesar de os logaritmos terem sido descobertos antes de se usarem expoentes.

Dados dois números reais positivos $a$ e $b$, onde $a>0, a \neq 1$ e $b>0$, existe somente um número real $x$, tal que $a^{x}=b$ ou ainda $\log _{a} b=x$, onde:

- $a=$ base do logaritmo

- $b=$ logaritmando

- $x=$ logaritmo 
Portanto, como exemplo, temos $\log _{3} 9=2$, pois $3^{2}=9$.

A base do logaritmo sempre deve ser um número positivo e diferente de 1.0 logaritmando sempre deve ser positivo.

De acordo com a definição, por exemplo:

- $\log _{2}(-9)$ deveria ser um único número $x$ tal que $2^{x}=-9$, o que é impossível, pois qualquer potência de base positiva é positiva.

- $\log _{1} 3$ deveria ser um único número $x$ tal que $1^{x}=3$, o que é impossível, pois qualquer potência de base 1 é igual a 1.

- $\log _{1} 1$ deveria ser um único número $x$ tal que $1^{x}=1$, porém existem infinitos valores de $x$ que satisfazem essa igualdade. 


\section{CAPÍTULO 2}

\section{FUNÇÕES LOGARÍTMICAS}

Nesse capítulo, a função logarítmica é apresentada como a inversa da função exponencial, sendo caracterizada a partir de sua propriedade de transformar produtos em somas. Além disso, define-se a função logaritmo natural por meio de uma integral.

\section{1 - A função logarítmica como inversa da exponencial}

Deve-se salientar que a descrição abaixo está fortemente baseada no texto apresentado no livro "A Matemática do Ensino Médio", volume 1 (LIMA et al., 2006). Primeiramente, toma-se que para todo número real positivo $a \neq 1$, a função exponencial $f: \mathrm{R} \rightarrow \mathbb{R}^{+}, f(x)=a^{x}$, é uma função bijetiva de $\mathrm{R}$ em $\mathbb{R}^{+}$, crescente se $a>1$, e decrescente se $0<a<1$, com a propriedade adicional:

$$
f(x+y)=f(x) . f(y) .
$$

Segue-se que $f$ possui uma função inversa. A inversa da função exponencial de base $a$ é a função

$$
\log _{a}: \mathrm{R} \rightarrow \mathrm{R}^{+} \text {, }
$$


que associa a cada número real positivo $x$ o número real $\log _{a} x$, chamado o logaritmo de $x$ na base $a$. Por definição de função inversa, tem-se

$$
a^{\log _{a} x}=x \quad \text { e } \quad \log _{a}\left(a^{x}\right)=x
$$

Assim, $\log _{a x}$ é o expoente ao qual se deve elevar a base a para obter o número $x$. Ou seja,

$$
y=\log _{a} X \Leftrightarrow a^{y}=x
$$

Segue-se imediatamente da relação $a^{u} \cdot a^{v}=a^{u+v}$ que

$$
\log _{a}(x y)=\log _{a} x+\log _{a} y
$$

para $x$ e $y$ positivos quaisquer. Com efeito, se $u=\log _{a} x$ e $v=\log _{a} y$ então $a^{u}=x$ e $a^{v}=$ $y, \log 0 x y=a^{u} \cdot a^{v}=a^{u+v}$, ou seja,

$$
\log _{a}(x y)=u+v=\log _{a} x+\log _{a} y
$$

Esta propriedade de transformar produtos em somas foi a motivação original para a introdução dos logaritmos no início do século XVII, e de sua popularidade, até bem recentemente, como um eficiente instrumento de cálculo. Ela também deu origem à construção das réguas de cálculo.

Segundo Lima et al. (2006), no livro a Matemática do Ensino Médio, a função logaritmo continua extremamente importante na Matemática e em suas aplicações. Essa importância é permanente; jamais desaparecerá porque, sendo a inversa da função exponencial (portanto equivalente a ela), a função logaritmo está ligada a um grande número de fenômenos e situações naturais, onde se tem uma grandeza cuja taxa de variação é proporcional à quantidade da mesma existente no instante dado.

A função $\log _{a}: \mathbb{R}^{+} \rightarrow \mathrm{R}$ é estritamente crescente quando $a>1$ e estritamente decrescente quando $0<a<1$. Como $a^{0}=1$, tem-se $\log _{a} 1=0$. Como o logaritmo é a inversa da função exponencial, que somente assume valores positivos, ressalta-se que somente os números positivos possuem logaritmo real. 
As funções logarítmicas mais comumente utilizadas são as de base 10 (logaritmos decimais), base 2 (logaritmos binários) e base $e$ (logaritmos naturais, às vezes impropriamente chamados neperianos).

Se $a>1$, a função $\log _{a} x$ é crescente; como $\log _{a} 1=0$, tem-se que $\log _{a} x<0$ se 0 $<x<1$ e $\log _{a} x>0$ se $x>1$. Se $0<a<1$, a situação se inverte: $\log _{a} x>0$ se $0<x<1$ e $\log _{a} x<0$ se $x>1$.

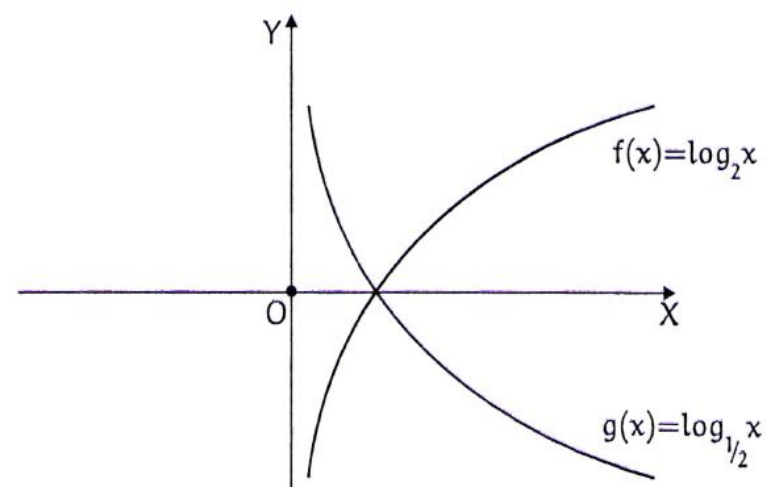

Gráfico 1 - Representação gráfica das funções $\mathrm{f}(\mathrm{x})=\log _{2} x$ e $g(x)=\log _{\frac{1}{2}} x$. Fonte: Lima, 2006, p. 192.

O Gráfico 1 representam as funções logarítmicas em geral, isto é, os gráficos das funções $y=\log _{a} x$ e $y=\log _{b} x$, com $a>1$ e $0<b<1$ têm o mesmo aspecto.

Como a função $\log _{a}: \mathrm{R}^{+} \rightarrow \mathrm{R}, a>1$, é bijetiva, ela é ilimitada tanto superiormente quanto inferiormente. Mais precisamente, tomando $a>1$, dado um número $T$, por maior que seja, tem-se $\log _{a} x>T$, desde que se tome um $x$ suficientemente grande. Do mesmo modo, tem-se $\log _{a} x<-T$, desde que se tome um $x>0$ suficientemente pequeno. Em símbolos:

$$
\begin{gathered}
\lim _{x \rightarrow+\infty} \log _{a} x=+\infty \\
\mathrm{e} \\
\lim _{x \rightarrow 0} \log _{a} x=-\infty
\end{gathered}
$$

Embora $\log _{a} x$ tenda a $+\infty$, quando $x$ tende a $+\infty$, esse crescimento é muito lento. Note que $\log _{10 x}$ em relação ao eixo x, então 


$$
\log _{10} 10^{\mathrm{n}}=\mathrm{n}
$$

para que $\log _{10} x>k$, para qualquer $k$, precisa-se tomar $x>10^{k}$.

\section{2 - Caracterização das Funções Logarítmicas}

Nessa subseção, busca-se caracterizar as funções logarítmicas a partir de sua propriedade de transformar produtos em somas.

Para isto, observa-se que, se $f: X \rightarrow Y$ é sobrejetiva e $g: Y \rightarrow X$ é tal que $g(f(x))$ $=x$ para todo $x \in X$, então $f$ é invertível e $g=f^{-1}$, a inversa de $f$. De fato, vamos mostrar que, como $f$ é sobrejetiva, para todo $y \in Y$ existe $x \in X$ tal que $f(x)=y$. Segue-se que

$$
f(g(y))=f(g(f(x)))=f(x)=y
$$

logo, $f$ é invertível e $g=f^{-1}$.

Em particular, se $f: \mathbb{R}^{+} \rightarrow \mathbb{R}$ é tal que $f\left(a^{x}\right)=x$ para todo $x \in \mathbb{R}$ então $f(y)=\log _{a} y$ para todo $y \in \mathbb{R}^{+}$.

Teorema (Caracterização das funções logarítmicas): Seja $f: \mathbb{R}^{+} \rightarrow \mathbb{R}$ uma função monótona injetiva (isto é, crescente ou decrescente), tal que $f(x y)=f(x)+f(y)$ para quaisquer $x, y \in \mathbb{R}^{+}$. Então existe $a>0$, tal que $f(x)=\log _{a} x$ para todo $x \in \mathbb{R}^{+}$.

Demonstração: Parte-se da análise do caso em que $f$ é crescente; o outro caso é tratado analogamente. Como $f(1)=f(1.1)=f(1)+f(1)$, tem-se $f(1)=0$. Como $f$ é crescente, tem-se $f(2)>0$; denota-se $b=f(2)$. Considera-se a função $g: \mathbb{R}^{+} \rightarrow \mathbb{R}$, definida por $g(x)=f(x) / b$ verifica $g(x y)=g(x)+g(y)$ e $g(2)=f(2) / b=1$.

Vamos mostrar que $g\left(2^{y}\right)=y$, para todo $y \in \mathbb{R}$. 
Em primeiro lugar, nota-se que para todo $y=n \in \mathbb{N}$ vale

$$
\begin{gathered}
g\left(2^{n}\right)=g(2 \cdot 2 \cdot \ldots \cdot 2)=g(2)+g(2)+\ldots+g(2)= \\
=1+1+\ldots+1=n .
\end{gathered}
$$

Além disso, como

$$
0=g(1)=g\left(2^{n} \cdot 2^{-n}\right)=g\left(2^{n}\right)+g\left(2^{-n}\right)=n+g\left(2^{-n}\right),
$$

tem-se

$$
g\left(2^{-n}\right)=-n
$$

Logo, $g\left(2^{y}\right)=y$, para todo $y \in \mathbb{Z}$.

Tome agora $r \in \mathbb{Q}$ : tem-se $r=n / m$, com $n \in \mathbb{Z}$ e $m \in \mathbb{N}$, então $r m=n$, e, portanto

$$
n=g\left(2^{n}\right)=g\left(2^{r m}\right)=g\left(\left(2^{r}\right)^{m}\right)=m \cdot g\left(2^{r}\right)
$$

e daí $g\left(2^{r}\right)=n / m=r$, para todo $r \in \mathbb{Q}$.

Dado $y \in \mathbb{R}$, irracional, então, para quaisquer $r, s$ racionais, com $r<y<s$ tem-se $2^{r}<2^{y}<2^{s}$, que implica $g\left(2^{r}\right)<g\left(2^{y}\right)<g\left(2^{s}\right)$, ou seja $r<g\left(2^{y}\right)<s$.

Através dessa demonstração, fica provado que todo número racional $r$, menor do que $y$, é também menor do que $g\left(2^{y}\right)$, e que todo número racional $s$ maior do que $y$ é também maior do que $g\left(2^{y}\right)$. Logo, $g\left(2^{y}\right)=y$ para todo $y \in \mathbb{R}$. Como $g$ é inversa da função exponencial $y \rightarrow 2^{y}$, tem-se $g(x)=\log _{2} x$ para todo $x>0$, que é equivalente a $x$ $=2 g(x)$. Assim

$$
x=2^{g(x)}=2^{f(x) / b}=\left(2^{1 / b}\right) f(x)=a^{f(x)}
$$

com $a=2^{1 / b}$. Logo, $f(x)=\log _{a} x$ para todo $x>0$. 


\section{3 - Logaritmo Natural}

Nos cursos de Cálculo, define-se a função logaritmo natural, ln $\mathbb{R}^{+} \rightarrow \mathbb{R}$, por meio de uma integral:

$$
\ln (\mathrm{x})=\int_{1}^{x} \frac{\mathrm{dt}}{t}, 0<x<\infty
$$

Em seguida, prova-se que:

$$
\ln (x y)=\ln (x)+\ln (y)
$$

Note que, pelo Teorema Fundamental do Cálculo, tem-se:

$$
\frac{\mathrm{d}}{\mathrm{dx}} \ln x=\frac{1}{x}>0
$$

para todo $x>0$. O Teorema do Valor Médio implica que ln é estritamente crescente no intervalo $(0,+\infty)$.

Usando a definição, tem-se que $\ln (x)<0$, se $0<x<1, \ln (1)=0$ e $\ln (x)>0$, se $x>1$.

A partir dessas informações, obtém-se a relação fundamental do logaritmo: "Se $a$ e $b$ são constantes positivas, então $\ln (a b)=\ln (a)+\ln (b)$."

Para demonstrar essa igualdade, considere a função

$$
g(x)=\ln (a x)-\ln (x)-\ln (a), \operatorname{com} x>0 .
$$

Pela regra da cadeia, tem-se

$$
\mathrm{g}^{\prime}(\mathrm{x})=\frac{\mathrm{d}}{\mathrm{dx}} \ln (\mathrm{ax})-\frac{\mathrm{d}}{\mathrm{dx}} \ln (\mathrm{x})=\frac{1}{a x} a-\frac{1}{x}=0, \text { para } \mathrm{x}>0 .
$$

O Teorema do Valor Médio implica que g é constante. Portanto $\mathrm{g}(\mathrm{x})=\mathrm{g}(1)$, para todo $x>0$. Mas $g(1)=0$. Logo 


$$
\ln (\mathrm{a} x)-\ln (x)-\ln (\mathrm{a})=0
$$

para todo $x>0$. Em particular, para $x=b$ tem-se

$$
\ln (\mathrm{a} b)-\ln (\mathrm{b})-\ln (\mathrm{a})=0
$$

ou seja,

$$
\ln (\mathrm{a} b)=\ln (\mathrm{a})+\ln (\mathrm{b})
$$

O objetivo aqui é provar a recíproca deste fato: se $\mathrm{f}: \mathbb{R}^{+} \rightarrow \mathbb{R}$ satisfaz (7), então f é dada por $\mathrm{f}(x)=\mathrm{k} \ln (x)$, para algum $\mathrm{k}$.

Considera-se assim o problema de encontrar todas as funções $f:(0,+\infty) \rightarrow \mathbb{R}$ que são deriváveis em $(0,+\infty)$ e satisfazem a igualdade

$$
f(x y)=f(x)+f(y)
$$

quaisquer que sejam $x>0$ e $y>0$.

Em primeiro lugar, tomando em (1) $x=y=1$ tem-se

$$
f(1)=f(1 \cdot 1)=f(1)+f(1)
$$

e, portanto, $f(1)=0$.

Agora, dado $b>0$, como $1=\mathrm{b} \cdot \frac{1}{\mathrm{~b}}$, tem-se

$$
0=f(1)=f\left(b \cdot \frac{1}{b}\right)=f(b)+f\left(\frac{1}{b}\right)
$$

que implica

$$
\mathrm{f}\left(\frac{1}{\mathrm{~b}}\right)=-\mathrm{f}(\mathrm{b})
$$

Combinando com (7) temos, quaisquer que sejam a $>0$ e b $>0$, 


$$
f\left(\frac{a}{b}\right)=f(a)-f(b)
$$

Vejamos como deve ser a derivada da função f. Tem-se, para cada a $>0$ e todo $\mathrm{h}$ tal que $\mathrm{a}+\mathrm{h}>0$.

$$
\frac{\mathrm{f}(\mathrm{a}+\mathrm{h})-\mathrm{f}(\mathrm{a})}{h}=\frac{1}{h} \mathrm{f}\left(\frac{\mathrm{a}+\mathrm{h}}{\mathrm{a}}\right)=\frac{\mathrm{f}(1+\mathrm{h} / \mathrm{a})}{h}
$$

Observando que $f(1)=0$ e multiplicando numerador e denominador por $1 / a$, temos

$$
\frac{f(1+h / a)}{h}=\frac{f(1+h / a)-f(1)}{h}=\frac{1}{a} \frac{f(1+h / a)-f(1)}{h / a}
$$

Chamando $\mathrm{k}=\frac{\mathrm{h}}{\mathrm{a}}$, podemos reescrever a igualdade acima como

$$
\frac{f(a+h)-f(a)}{h}=\frac{1}{a} \frac{f(1+h / a)-f(1)}{h / a}=\frac{1}{a} \frac{f(1+k)-f(1)}{k}
$$

e, portanto, tem-se,

$$
f^{\prime}(a)=\lim _{h \rightarrow 0} \frac{f(a+h)-f(a)}{h}=\frac{1}{a} \lim _{k \rightarrow 0} \frac{f(1+k)-f(1)}{k}=\frac{1}{a} f^{\prime}(1)
$$

Assim, as funções que verificam (7) e são deriváveis em $(0,+\infty)$ satisfazem

$$
f^{\prime}(x)=\frac{1}{x} f^{\prime}(1)
$$

para todo $x>0$. Integrando (8) e lembrando que $f(1)=0$, tem-se

$$
f(x)=f^{\prime}(1) \int_{1}^{x} \frac{d t}{t}
$$


Logo, cada escolha do valor $f$ ' $(1)$ determina uma função $f$ nas condições acima. Quando tomamos $f^{\prime}(1)=1$, tem-se o logaritmo natural. Mais precisamente, a função ln : $(0,+\infty) \rightarrow \mathbb{R}$ definida por

$$
\ln (x)=\int_{1}^{x} \frac{\mathrm{dt}}{\mathrm{t}},
$$

para todo $x>0$, chama-se logaritmo natural. 


\section{CAPÍTULO 3}

\section{A RÉGUA DE CÁLCULO}

Nos séculos XVI e XVII, os cálculos astronômicos e científicos demandavam resoluções rápidas de operações de multiplicação e divisão tanto de números muito grandes quanto de números muito pequenos. Com a descoberta dos logaritmos foi possível simplificar tais problemas, pois um produto pode ser transformado em uma adição e uma divisão numa subtração.

As facilidades trazidas pelos logaritmos estão ligadas às suas propriedades. Uma delas diz que o logaritmo do produto de dois números é igual à soma dos logaritmos desses números:

$$
\log x \cdot y=\log x+\log y
$$

Outra dessas propriedades mostra que o logaritmo da divisão de dois números é igual à diferença dos logaritmos desses números.

$$
\log \left(\frac{x}{y}\right)=\log x-\log y
$$

Essas propriedades simplificaram os cálculos de operações com grandezas elevadas, utilizando dispositivos como a régua de cálculo e, posteriormente, os computadores.

Segundo Eves (2004, p. 352),

acredita-se que Oughtred tenha sido o autor do notável apêndice anônimo de dezesseis páginas da tradução inglesa da Descriptio de Napier, editada por Edward Wright, em 1618. Nesse apêndice, usase pela primeira vez o símbolo (x) para a multiplicação e o método da raiz para o cálculo de logaritmos e aparece também a primeira tábua de logaritmos naturais. 
John Napier inventou a "Tábua de Napier", parecida com uma tabela de multiplicações. Através da utilização dessas tábuas era possível reduzir multiplicações e divisões a adições e subtrações. Com esse princípio, William Oughtred, um sacerdote inglês, publicou, em 1632, a obra The Circles of Proportion (Os Círculos de Proporção), na qual descreve um instrumento de cálculo que daria origem à régua de cálculo. Os círculos de proporção consistiam de duas peças de madeira na qual estavam assinalados números em uma escala logarítmica. No entanto, não foi a primeira descrição a aparecer impressa, e a questão da prioridade da invenção pende entre ele e Richard Delamain, um de seus discípulos. Credita-se a Oughtred a invenção da régua de cálculo logarítmica reta, por volta de 1622, a qual facilitava a realização de cálculos que não exigissem tanta precisão, usando os logaritmos de Napier.

O desenvolvimento da régua de cálculo está fortemente relacionado com a propriedade fundamental de logaritmo, que "transforma" produtos em somas. Como os logaritmos são representados por traços na régua e sua divisão e produto são obtidos pela adição e subtração de comprimentos, a régua de cálculo é considerada como o primeiro computador analógico da história. As réguas de cálculo foram utilizadas como instrumento de cálculo por mais de trezentos anos, até o surgimento do primeiro computador, em 1930. Em alguns relatos, aponta-se o uso das réguas de cálculo até 1970, antes das calculadoras de bolso.

Segundo Eves (2004, p. 350), em 1620, Edmund Gunter (1581-1626) construiu uma escala logarítmica reta em que as distâncias entre os números são proporcionais aos logaritmos dos números indicados, isto é, partindo de um ponto de origem, marcam-se segmentos com comprimento proporcional aos logaritmos dos números indicados no instrumento (PASTORE, 20--).

Com essa escala, multiplicações e divisões eram efetuadas somando-se e subtraindo-se os segmentos da escala, com a ajuda de um par de ponteiros operando como um compasso.

Podia-se multiplicar dois números pela soma da medida da distância do início da escala para o primeiro fator e a distância correspondente ao segundo fator. Para multiplicar $2 \times 3$, por exemplo, temos o seguinte processo, que foi descrito por Guimarães (200-): 
a) Posiciona-se a escala sobre a folha de papel (Figura 3.1) e marca-se um ponto de referência para o primeiro número (1) e um ponto de referência para o segundo número (2):

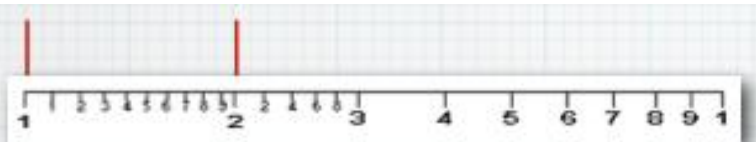

Figura 3.1 - Uso da régua no cálculo $2 \times 3$, primeiro passo. Fonte: Guimarães, [200-].

b) Desloca-se a escala de modo que o número 1 fique posicionado sob o ponto que foi marcado para o número 2 (Figura 3.2). Marca-se então o local do segundo fator (número 3):

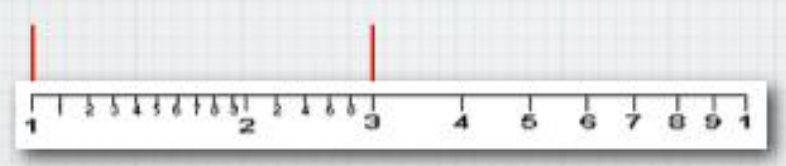

Figura 3.2 - Uso da régua no cálculo 2 × 3 , segundo passo. Fonte: Guimarães, [200-].

c) Volta-se a escala para a posição original (Figura 3.3):

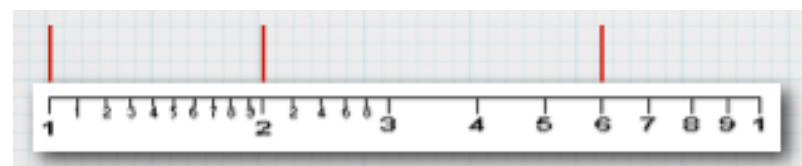

Figura 3.3 - Uso da régua no cálculo 2 × 3 , terceiro passo. Fonte: Guimarães, [200-].

d) O número que se encontra abaixo da última marca é o produto de 2 x 3: o número 6 (Figura 3.4). Assim o produto $2 \times 3$ foi transformado na soma $2+3$ : 


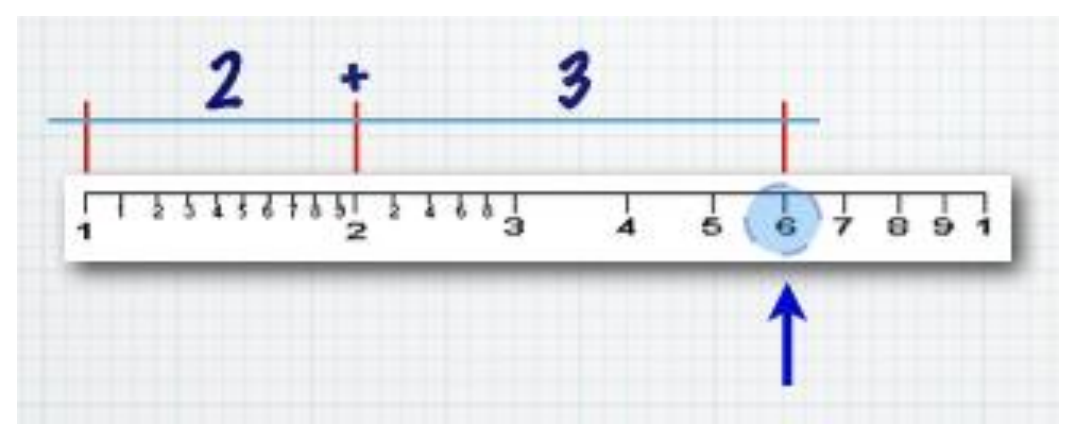

Figura 3.4 - Uso da régua no cálculo 2 x 3, quarto passo. Fonte: Guimarães, [200-].

Segundo Eves (2004, p. 350), Oughtred passou a efetuar adições e subtrações com duas escalas logarítmicas, uma deslizando ao longo da outra, como está descrito na Figura 4, simplificando bastante o processo apresentado anteriormente. Esse modo de utilizar as escalas logarítmicas diferenciava-se do processo executado por Gunter, pois desprezava as marcações feitas no papel.

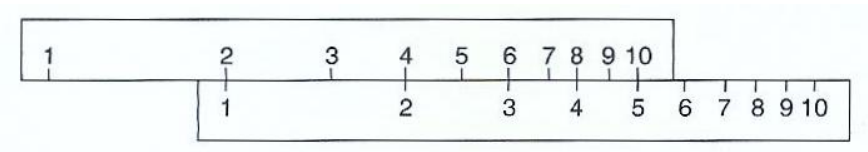

Figura 4 - Uso de duas escalas no cálculo, segundo Oughtred.

Fonte: Eves, 2004, p. 352.

Segundo Eves (2004, p.350), Isaac Newton sugeriu, em 1675, um trilho para a régua de cálculo, mas essa ideia só veio a ser concretizada quase um século mais tarde. Portanto, para realizar operações com as propriedades dos logaritmos na régua de cálculo, podemos seguir os seguintes passos apresentados por Campagner (200-?):

a) Primeiramente, toma-se um papel em escala logarítmica, mantendo a escala na base superior do retângulo, como o da Figura 5;

b) Constrói-se outro desenho da escala logarítmica, agora, mantendo a escala logarítmica na base inferior do retângulo;

c) Aproxima-se um retângulo do outro, de modo que o número 2 da escala superior esteja alinhado com o número 1 da escala inferior. Desse modo, estar-se-á trabalhando com os produtos de uma multiplicação pelo número 2 . 


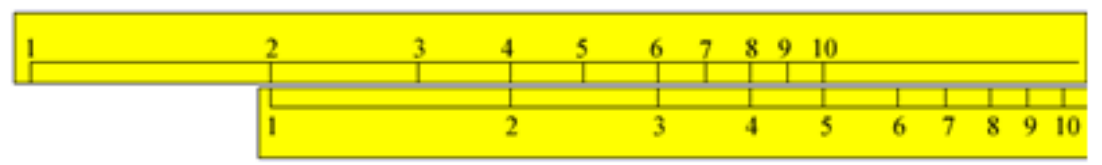

Figura 5 - Régua na posição da multiplicação por 2.

Fonte: Campagner, [200-?].

Note que o número 2 da régua de baixo, encontra-se com o número 4 da régua de cima. Acima do 3 , temos 6 . Isto é, $2 \times 2=4,2 \times 3=6$, etc.

A Figura 6 ilustra o exemplo da utilização da régua para o número 3:

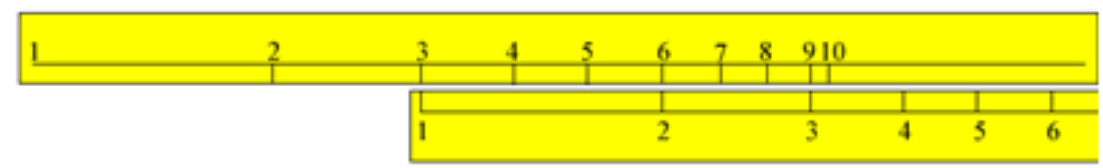

Figura 6 - Régua na posição da multiplicação por 3.

Fonte: Campagner, [200-?].

Nesse exemplo, percebe-se que a régua efetua a soma dos logaritmos. Alinhando os números 3 e 1, pode-se efetuar a multiplicação pelo fator 3 . Efetuandose a multiplicação de 3 por 2, soma-se o segmento logaritmo de 3 com o segmento logaritmo de 2 que resulta o segmento logaritmo de 6.

Note que a operação inversa é possível (divisão). Na divisão, realizamos o mesmo procedimento, porém em ordem inversa, ou seja, para dividir 6 por 2, faz-se coincidir o 6 da escala superior com o 2 da escala inferior. Encontraremos o número 3 na escala superior, acima do número 1. Portanto, 3 é o resultado da divisão de 6 por 2.

Diferentemente da calculadora, o uso da régua de cálculo não diminui, mas estimula o raciocínio, pois para multiplicar, por exemplo, 0,0034 por 567 é necessário multiplicar 3,4 por 5,67 e trabalhar com potência de dez.

No exemplo acima, a multiplicação $3 \times 2=6$ é a mesma para $30 \times 20=600$, ou então, $0,3 \times 200=60$.

Como ambas as escalas são logarítmicas, o deslocamento entre a escala superior e a escala inferior simplesmente soma os logaritmos, já que a soma dos logaritmos é o logaritmo do produto dos respectivos números. Podemos dizer que 3 x $2=6$, então $\log 3+\log 2=\log (3 \times 2)=\log 6$. 
A régua de cálculo era o melhor instrumento de cálculo existente até ser criado o computador na década de 1940, com a desvantagem de trabalhar somente com três algarismos significativos. Assim, uma operação como 1.285 x 3.692 é resolvida facilmente com uma régua de cálculo, mas, o máximo que será possível dizer do resultado é que ele está bem próximo de 4.740 .000 e raramente o valor exato (4.744.220, neste caso).

Com a régua de cálculo não é possível fazer somas, apesar de que, se as escalas não fossem logarítmicas, mas sim lineares, as operações de multiplicação e divisão seriam, respectivamente, soma e subtração, pois elas somam e subtraem os logaritmos.

Em 1628, Edmund Wingate e depois, em 1630, William Oughtred (1574-1660) inseriram a mesma escala em duas réguas que corriam uma ao lado da outra, eliminando o uso do compasso e apresentando a régua de cálculo no formato abaixo (Figura 7), o qual está relacionado com a forma atual.

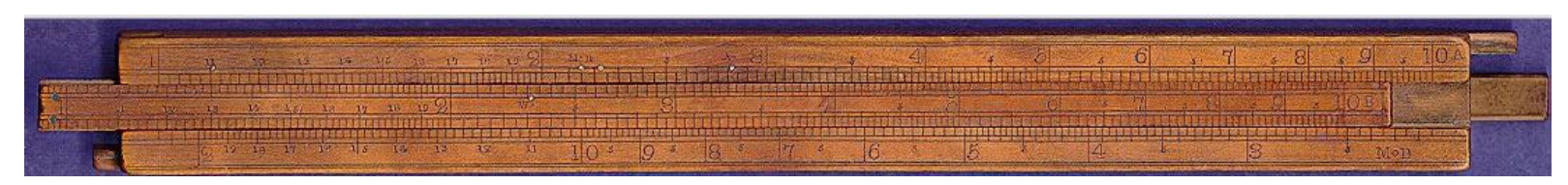

Figura 7 - Forma atual da régua de cálculo.

Fonte: Site Giovanni Pastore ${ }^{4}$.

A régua de cálculo é composta por escalas fixas e móveis e, em cada uma destas partes, estão distribuídas outras escalas. As escalas mais comuns presentes numa régua de cálculo são as escalas apresentadas na Figura 8, no entanto existem muitas outras escalas, inclusive réguas com diversas partes móveis com escalas intercambiadas na parte fixa para expandir as possibilidades de cálculos.

\footnotetext{
${ }^{4}$ Disponível em <http://www.giovannipastore.it/index_file/regolo_ATT.JPG>. Acesso em: 25 mai. 2013.
} 


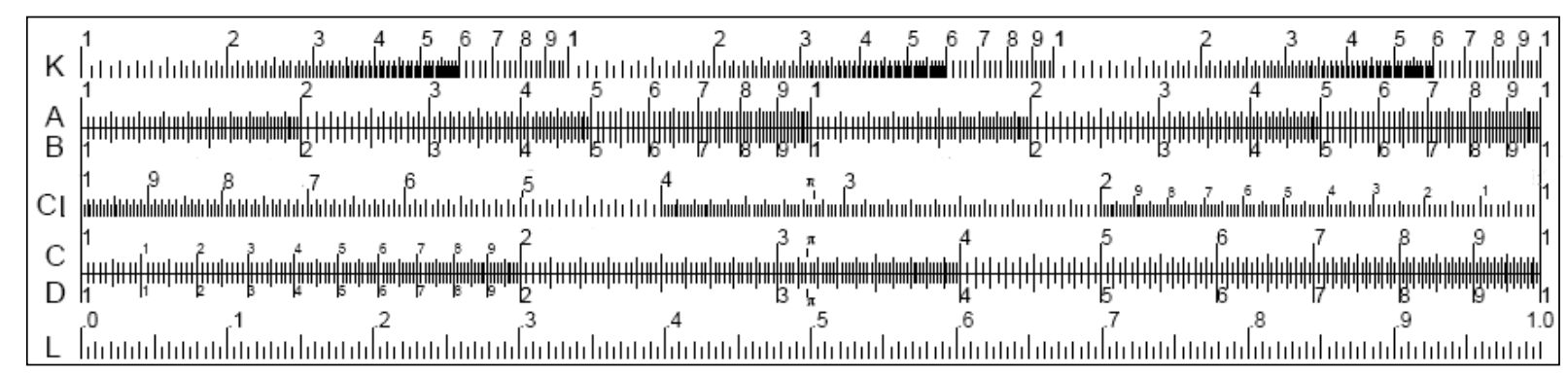

Figura 8 - Forma comum de régua de cálculo.

Fonte: Wikipedia Commons ${ }^{5}$.

$\mathrm{Na}$ Tabela 4, encontramos algumas das escalas presentes na régua acima (Figura 8):

Tabela 4 - escalas presentes na Figura 8.

\begin{tabular}{|c|c|c|}
\hline \multicolumn{3}{|r|}{ Escalas básicas } \\
\hline$A$ e $B$ & $X^{2}$ & $\begin{array}{l}\text { Duas décadas - usadas em multiplicações, divisões, raiz quadrada e } \\
\text { quadrados. }\end{array}$ \\
\hline C e D & $X$ & $\begin{array}{l}\text { Uma década - usada em multiplicações, divisões, raiz quadrada e cúbica e } \\
\text { quadrados e cubos. }\end{array}$ \\
\hline $\mathrm{Cl}$ e DI & $\frac{1}{X}$ & As escalas C e D em ordem inversa - usadas em operações de inverso \\
\hline K & $X^{3}$ & Três décadas - usada em operações de raiz cúbica e cubos \\
\hline L & $\log X$ & Escala linear - usada para logaritmo de base 10 \\
\hline
\end{tabular}

No século XVII, inventaram-se vários tipos de régua de cálculo para propósitos especiais, como transações comerciais, medida de vigas de madeira e outros. Além da parte fixa e da móvel, a régua tem ainda o cursor que é uma janela móvel com uma linha fina que permite alinhar os pontos em escalas não adjacentes (Figura 9).

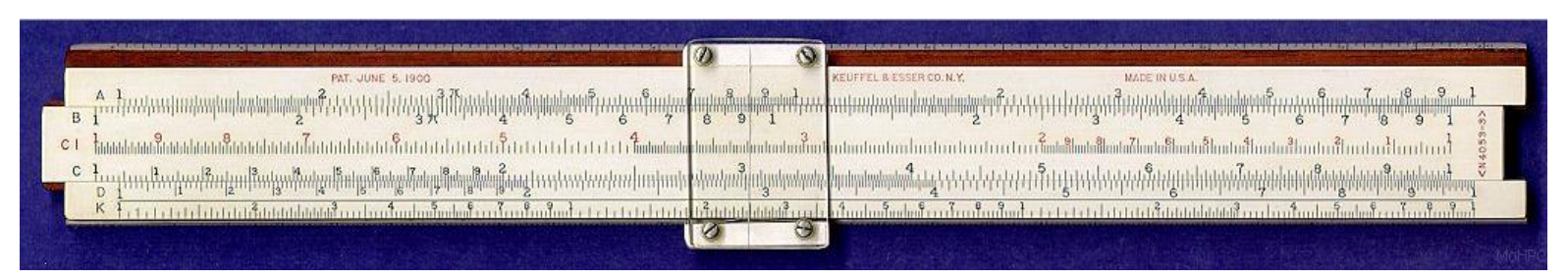

Figura 9 - Régua de cálculo com cursor móvel Fonte: Site Giovanni Pastore ${ }^{6}$.

\footnotetext{
${ }^{5}$ Disponível em: < http://commons.wikimedia.org/wiki/File:Regua_calculo.png>. Acesso em: 25 mai. 2013.
} 
O desenvolvimento e a maior utilização da régua de cálculo deram-se à medida que cresciam as exigências dos cálculos científicos e técnicos da primeira revolução industrial, sendo a mesma pouco utilizada durante quase 200 anos após a sua criação, nos anos do Renascimento Científico europeu. No final do século XVIII, James Watt (1736-1819), após uma reavaliação da importância e da demanda da régua de cálculo no mercado, tornou possível sua fabricação em grande escala.

Durante anos, ensinou-se a calcular com logaritmos na escola de segundo grau (atual ensino médio) ou no início dos cursos superiores de matemática. Também, por muitos anos, a régua de cálculo logarítmica foi um instrumento indispensável para os engenheiros e cientistas.

Além de a régua cálculo logarítmica ter sido construída em vários materiais, possui também diversas formas e dimensões, com formas lineares (Figura 10), circulares (anel matemático, Figura 11) e cilíndricas (Figura 12), sendo utilizada em cada campo da ciência e da técnica graças às várias versões adaptadas às variadas disciplinas da engenharia.

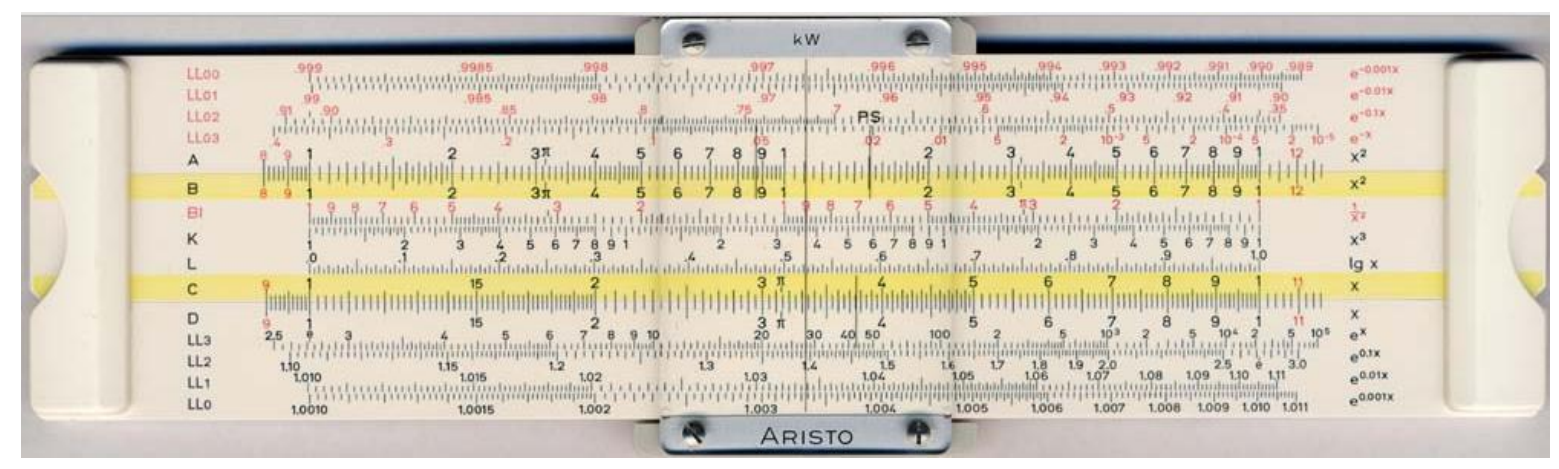

Figura 10 - Régua de cálculo em forma linear. Fonte: Site Giovanni Pastore ${ }^{7}$.

${ }^{6}$ Disponível em: <http://www.giovannipastore.it/index_file/regolo_LEG.JPG>. Acesso em: 25 mai. 2013.

${ }^{7}$ Disponível em <http://www.giovannipastore.it/index_file/regolo_PLA.jpg>. Acesso em: 25 mai. 2013 


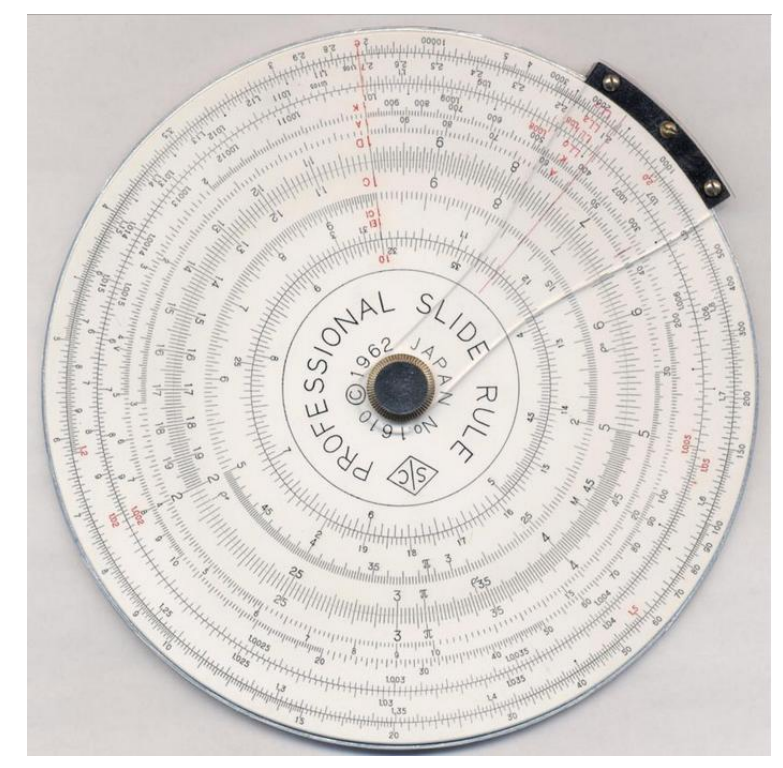

Figura 11 - Régua de cálculo em forma circular. Fonte: Site Giovanni Pastore ${ }^{8}$.

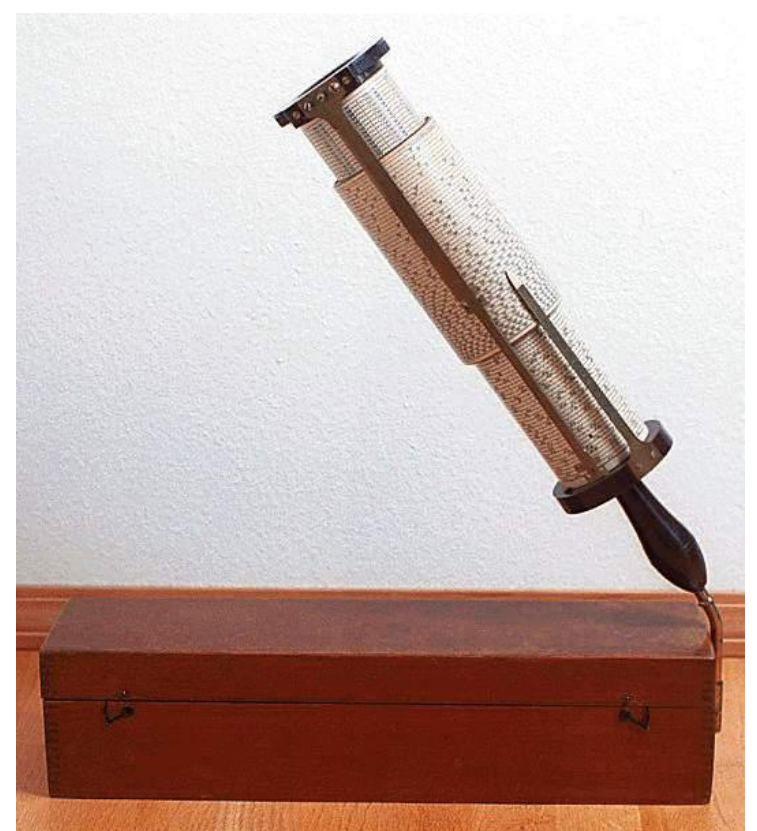

Figura 12 - Régua de cálculo em formato cilíndrico. Fonte: Site Giovanni Pastore ${ }^{9}$.

Além dos cálculos de funções matemáticas (das raízes aos expoentes, dos logaritmos às funções trigonométricas), muitas réguas de cálculo foram desenvolvidas para resolver cálculos especiais, por exemplo, no campo da mecânica, da aeronáutica, da química, da eletrônica, da topografia, do comércio etc. (Figuras 13 a 16).

\footnotetext{
${ }^{8}$ Disponível em <http://www.giovannipastore.it/index_file/regolo_CIR.jpg>. Acesso em: 25 mai. 2013.

${ }^{9}$ Disponível em: <http://www.giovannipastore.it/index_file/regolo_CIL.JPG>. Acesso em 25 mai. 2013.
} 


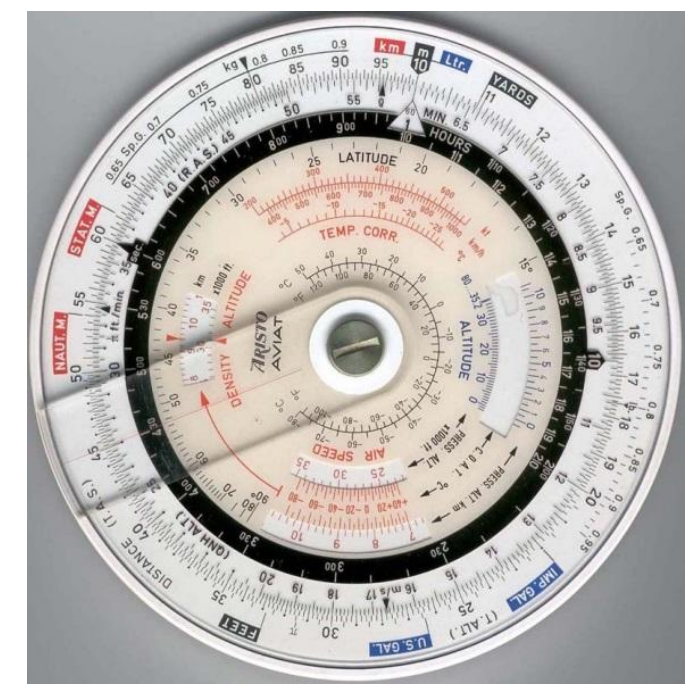

Figura 13 - Régua de cálculo circular utilizada na aviação. Fonte: Site Giovanni Pastore ${ }^{10}$.

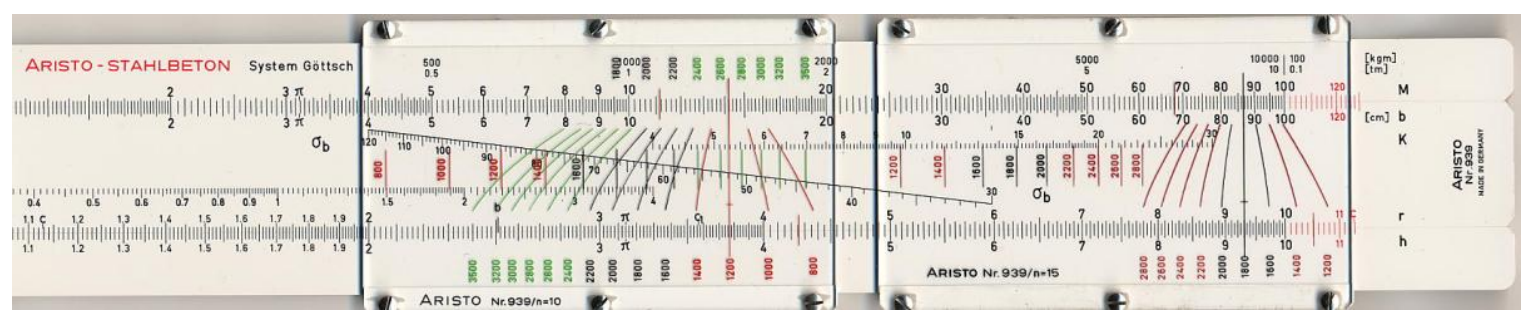

Figura 14 - Régua de cálculo linear utilizada para avaliação de estruturas em cimento, própria para canteiro de obras. Fonte: Site Giovanni Pastore ${ }^{11}$.

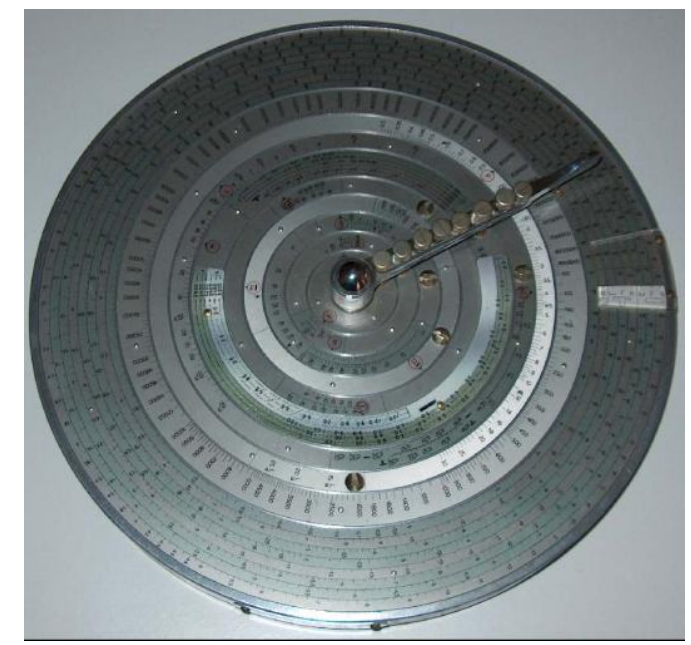

Figura 15 - Régua de cálculo circular de mesa, utilizada para avaliação de estruturas em cimento. Fonte: Site Giovanni Pastore ${ }^{12}$.

\footnotetext{
10 Disponível em: <http://www.giovannipastore.it/index_file/regolo_AVI.jpg>. Acesso em: 25 mai. 2013.

${ }_{11}$ Disponível em: <http://www.giovannipastore.it/index_file/regolo_CEM.JPG>. Acesso em: 25 mai. 2013.
} 


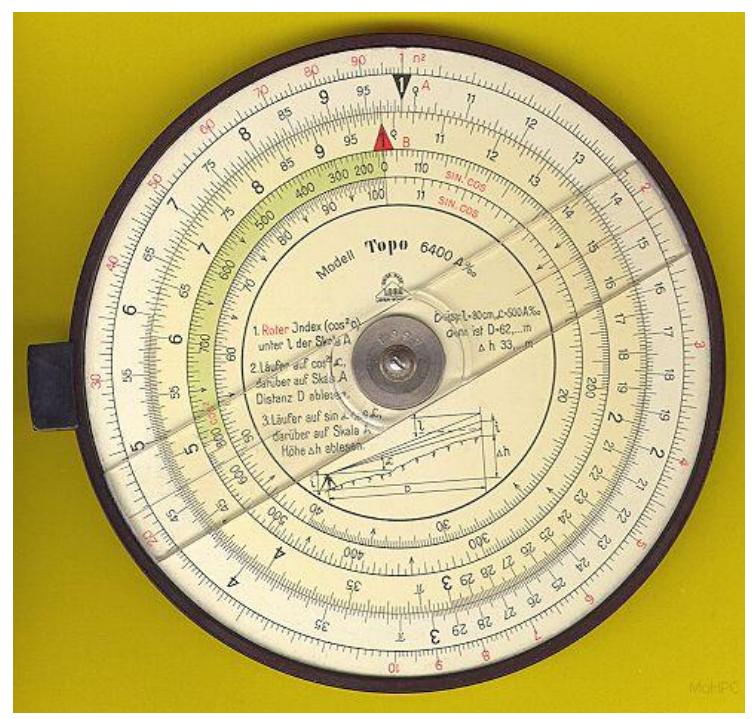

Figura 16 - Régua de cálculo circular de mesa, utilizada para topografia. Fonte: Site Giovanni Pastore ${ }^{13}$.

Segundo Pastore (20--),

Até os anos 70 , as réguas de cálculo logarítmicas foram os únicos instrumentos de cálculo científico de massa, tanto que se tornaram o símbolo da tecnologia e dos cálculos de engenharia. As réguas de cálculo eram o instrumento fundamental para os engenheiros, matemáticos e físicos. (...) Com as réguas de cálculo foram calculados até trinta anos atrás: pontes, edifícios, navios, aviões, automóveis e tantos outros produtos da ciência e da tecnologia. (...) As réguas de cálculo não são objetos do passado. Algumas estão ainda em produção e são utilizadas no campo da aeronáutica e nos campos instrumentístico e técnicos, porque são mais práticas e velozes nos cálculos específicos.

12 Disponível em: <http://www.giovannipastore.it/index_file/regolo_CEM_TAV.jpg>. Acesso em: 25 mai. 2013.

${ }_{13}$ Disponível em: <http://www.giovannipastore.it/index_file/regolo_TOP.JPG>. Acesso em: 25 mai. 2013. 


\section{CAPÍTULO 4}

\section{SEQUÊNCIA DIDÁTICA PARA A UTILIZAÇÃO DA RÉGUA DE CÁLCULO EM SALA DE AULA}

No estudo da Matemática no Ensino Médio, o conceito de funções exponenciais e logarítmicas está entre os mais importantes. Os logaritmos são uma invenção genial do século XVII, pois foram capazes de simplificar cálculos enormes num período de limitados instrumentos para tal feito.

De acordo com os Parâmetros Curriculares Nacionais para o Ensino Médio (1998, p. 120),

a aprendizagem não se dá com o indivíduo isolado, sem possibilidade de interagir com seus colegas e com o professor, mas em uma vivência coletiva de modo a explicitar para si, e para os outros, o que pensa e as dificuldades que enfrenta.

Por esse motivo, é importante que, ao estudar os logaritmos, os alunos encontrem uma forma de interação com os colegas, tornando o ensino das propriedades dos logaritmos algo mais que simples memorização de fórmulas. Nesse intuito, este texto propõe o trabalho com a régua de cálculo, para que os alunos falem sobre matemática e tenham a oportunidade de aprender de uma forma contextualizada, integrada e relacionada a outros conhecimentos, desenvolvendo competências e habilidades que possibilitem argumentar, analisar, avaliar e tirar conclusões próprias, pois o pensar e o fazer se mobilizam e se desenvolvem quando o aluno está engajado ativamente no enfrentamento de desafios.

$O$ assunto logaritmo é ensinado ao longo do terceiro bimestre da primeira série do ensino médio, enfocando as funções exponencial e logarítmica, com destaque para o crescimento exponencial. Para o estudo dos logaritmos, é imprescindível compreender o significado dos logaritmos como expoentes convenientes para a representação de números muito grandes ou muito pequenos e conhecer as principais propriedades dos logaritmos, a representação da função 
logarítmica como inversa da exponencial, bem como saber resolver equações e inequações simples, usando propriedades de potências e logaritmos.

Após o estudo das ideias de potências e logaritmos, com o entrelaçamento de suas propriedades, faz-se necessário a apresentação de um panorama de contextos em que tais ideias encontram-se presentes, resolvendo equações e inequações em contextos significativos, tais como fenômenos naturais de diversos tipos.

As funções exponencial e logarítmica, por exemplo, são usadas para descrever a variação de duas grandezas em que o crescimento da variável independente é muito rápido, sendo aplicada em áreas do conhecimento, como matemática financeira, crescimento de populações, intensidade sonora, $\mathrm{pH}$ de substâncias e outras. (BRASIL, 2002, P. 121).

No entanto, não adianta falar somente em escala Richter para jovens que vivem num país onde quase nunca há terremotos. Pouco será entendido pelos jovens quando se falar de $\mathrm{pH}$ para aqueles que não se veem, no futuro, trabalhando como químicos ou engenheiros ou farmacêuticos. É importante ressaltar para os alunos que os logaritmos aparecem no estudo dos sons e da música; aparecem na astronomia; aparecem na economia e na ciência da computação, sendo muito utilizados na própria matemática, como, por exemplo, na teoria dos números e no cálculo.

Segundo os PCN+ (BRASIL, 2002, p. 121), para o ensino da matemática,

o estudo das funções permite ao aluno adquirir a linguagem algébrica como a linguagem das ciências, necessária para expressar a relação entre grandezas e modelar situações-problema, construindo modelos descritivos de fenômenos e permitindo várias conexões dentro e fora da própria matemática. Assim, a ênfase do estudo das diferentes funções deve estar no conceito de função e em suas propriedades em relação às operações, na interpretação de seus gráficos e nas aplicações dessas funções.

Para tornar o ensino de logaritmos mais significativo para os alunos, foi elaborada uma sequência didática, iniciada com a apresentação das propriedades dos logaritmos, para, a partir delas, facilitar a construção do conceito de logaritmo e apresentar uma análise detalhada dessas propriedades operatórias. Para isso, buscou-se introduzir o trabalho com a régua de cálculo, em sala de aula.

A sequência foi aplicada em uma sala de primeira série do Ensino Médio, com 31 alunos, na Escola Estadual Dr. Francisco da Cunha Junqueira - Bonfim Paulista 
- Ribeirão Preto/SP, utilizando recursos como pesquisas feitas pelos alunos, leitura de texto do livro didático adotado, leitura de texto do Caderno do Aluno do Currículo Oficial do Estado de São Paulo (SÃO PAULO, 2013a), utilização de folhas de atividades que trabalham as propriedades dos logaritmos, utilização de um texto sobre régua de cálculo, utilização de uma régua de cálculo reproduzida em papel. 0 registro fotográfico, o instrumento utilizado (régua de cálculo) e relatos produzidos por dois alunos após a sequência didática constam em anexo a este trabalho.

Inicialmente, os alunos fizeram uma pesquisa sobre os seguintes temas: a história dos logaritmos, condições de existência de um logaritmo e propriedades operatórias dos logaritmos. A classe foi dividida em nove grupos. Após o trabalho de pesquisa, os alunos apresentaram os trabalhos em forma de seminário.

A pesquisa teve como objetivo levar os alunos a ler textos sobre logaritmos, para que se apropriassem do conteúdo a ser trabalhado. Cada grupo apresentou suas observações para os demais alunos da classe, utilizando cartazes, que continham uma síntese do que foi pesquisado.

$\mathrm{Na}$ aula seguinte, após a apresentação do seminário, inicialmente foi apresentado o texto "Os fundamentos da Teoria dos Logaritmos" (PAIVA, 2010), o qual trata do princípio básico dos logaritmos: a transformação de uma multiplicação em adição ou uma divisão em subtração. Foi distribuída aos alunos uma tabela contendo três colunas (Tabela 5), com o título "Calculadoras Rudimentares" (como o sugerido em CÁLCULO, 2013, p.43 a p.54). A primeira coluna já estava numerada de 1 a 20. As outras duas colunas foram preenchidas pelos alunos da seguinte maneira: na coluna do meio foi solicitado que escrevessem uma sequência, iniciando pelo número zero, onde cada termo posterior fosse igual ao anterior mais quatro unidades e, na terceira coluna, uma sequência iniciando pelo número 1, onde cada termo posterior fosse igual ao triplo do termo anterior. Na verdade, os alunos construíram uma progressão aritmética (PA) na segunda coluna e uma progressão geométrica $(P G)$ na terceira coluna.

Até $\mathrm{o}$ preenchimento da décima quinta linha, os alunos fizeram todos os cálculos manualmente. A partir da décima sexta linha, foi permitido o uso da calculadora em razão dos cálculos com números muito grandes.

Após completar todo o quadro, multiplicaram o termo da PG da linha quatro pelo termo na linha dez. Foi muito trabalhoso realizar a multiplicação dos números 
27 por 19.683, para obter o resultado 531.441. O produto foi conferido com o auxílio da calculadora.

O próximo passo foi multiplicar o termo da progressão geométrica na linha dois pelo termo na linha onze, ou seja, 3 por 59.049, para obter 177.147.

Por último, foi solicitada a multiplicação do termo da PG na linha seis pelo termo na linha treze, ou seja, 243 por 531.441, obtendo 129.140.163.

O objetivo dessa atividade é perceber que multiplicar um termo da PG por outro termo da PG é equivalente a somar o termo da PA ao lado do primeiro termo da PG ao termo da PA ao lado do segundo termo da PG. O resultado da adição cai na mesma linha que o resultado da multiplicação. Ao termo da PA, ao lado do termo da PG numa determinada linha, pode-se dar o nome de logaritmo.

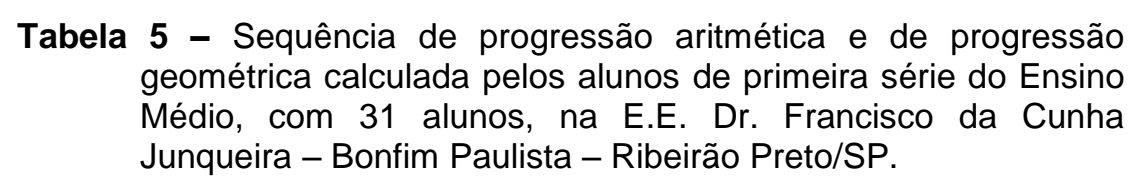

\begin{tabular}{crr}
\hline Linha & PA & \multicolumn{1}{r}{ PG } \\
\hline 1 & 0 & 1 \\
2 & 4 & 3 \\
3 & 8 & 9 \\
4 & 12 & 27 \\
5 & 16 & 81 \\
6 & 20 & 243 \\
7 & 24 & 729 \\
8 & 28 & 2.187 \\
9 & 32 & 6.561 \\
10 & 36 & 19.683 \\
11 & 40 & 59.049 \\
12 & 44 & 177.147 \\
13 & 48 & 531.441 \\
14 & 52 & 1.594 .323 \\
15 & 56 & 4.782 .969 \\
16 & 60 & 14.348 .907 \\
17 & 64 & 43.046 .721 \\
18 & 68 & 129.140 .163 \\
19 & 72 & 387.420 .489 \\
20 & 76 & 1.162 .261 .467 \\
\hline
\end{tabular}

Fonte: Cálculo, 2013, p.43 a p.54. 
Os alunos foram levados a perceber que através da utilização dessa calculadora rudimentar é possível obter o resultado da multiplicação depois de fazer uma soma bem simples. Também foram levados a perceber que é possível dividir dois números da $P G$, pois isso equivale a subtrair os números chamados de logaritmos na PA.

Cada termo da PA pode ser chamado de logaritmo porque ele é um logaritmo de base $3^{\frac{1}{4}}=\sqrt[3]{4}$ do termo da PG.

Nesse momento, foi apresentada a régua de cálculo.

Após construir o conceito de que os logaritmos nada mais são que expoentes, apresentou-se a ideia de que suas propriedades decorrem das correspondentes propriedades das potências. Os alunos manusearam a régua de cálculo, com os cálculos de $\log 4, \log 6, \log 8$ e $\log 10$ e efetuaram diversas multiplicações (conforme salientado no Capítulo 3, Figuras 3.1 a 3.4).

Para o trabalho com a régua de cálculo, as atividades foram desenvolvidas em duplas. Os resultados foram obtidos através da análise das atividades realizadas pelos estudantes e também da observação e dos registros feitos durante a aplicação da sequência. Observou-se que os alunos adquiriram maior entendimento das propriedades logarítmicas através do manuseio da régua de cálculo.

Posteriormente, foi discutida a Situação de Aprendizagem no 2 (SÃO PAULO, 2013), com o objetivo de explorar as ideias de potências e de expoentes. De acordo com o Caderno do Professor, Volume 3, da 1ํㅗㄹ série do Ensino Médio (SÃO PAULO, 2013b, p. 28),

quem afirma, por exemplo, que, para multiplicar potências de mesma base, mantém-se a base e somam-se os expoentes, ou seja, que $a^{\mathrm{m}} \cdot a^{\mathrm{n}}=a^{\mathrm{m}+\mathrm{n}}$, está simultaneamente afirmando que o expoente a que se deve elevar a base $a$ para se obter o produto $\left(a^{\mathrm{m}} \cdot a^{\mathrm{n}}\right)$ é igual a $(m+n)$, o que significa dizer que o logaritmo de $\left(a^{m} \cdot a^{n}\right)$ é igual a $(m+n)$. Em outras palavras, o logaritmo do produto é igual à soma dos logaritmos dos fatores.

As propriedades são válidas, portanto, qualquer que seja a base a em que estamos calculando os logaritmos.

No final da aula, foi apresentado aos alunos o texto do Anexo A, que trata das propriedades dos logaritmos, bem como a colocação a seguir (conforme salientada no Capítulo 1), como conclusão do trabalho realizado. 
Dados dois números reais positivos $a$ e $b$, onde $a>0, a \neq 1$ e $b>0$, existe somente um número real $x$, tal que $a^{x}=b$ ou ainda $\log _{a} b=x$, onde:

- $a$ = base do logaritmo

- $b=$ logaritmando

- $x=$ logaritmo

Portanto, $\log _{3} 9=2$, pois $3^{2}=9$

A base do logaritmo sempre dever ser um número positivo e diferente de 1 . 0 logaritmando sempre deve ser positivo. 


\section{CONSIDERAÇÕES FINAIS}

No início do trabalho, apresentou-se um estudo sobre as barras de Napier e sobre as regras de prostaférese. Tinha-se, nesse momento, a intenção de promover uma atividade que trouxesse às aulas de logaritmos um trabalho concreto, para que os alunos não ficassem somente com a teoria dos logaritmos, mas percebessem de onde surgiu a ideia que contribuiu para simplificar cálculos com números muito grandes ou muito pequenos.

$\mathrm{Na}$ preparação do seminário, houve receio quanto ao trabalho que seria apresentado pelos alunos, pois não se sabia se os mesmos demonstrariam ou não interesse pelo assunto. Quando os alunos realizaram a apresentação dos temas, percebemos que muitos deles estudaram verdadeiramente os conteúdos, assistindo a vídeos disponíveis na internet e fazendo pesquisas em livros didáticos disponíveis na biblioteca da escola.

Os trabalhos dos alunos abordaram a ideia de potência, os gráficos crescente e decrescente da função logarítmica, a história do surgimento dos logaritmos, as suas propriedades, as condições de existência de um logaritmo e a régua de cálculo.

Quando da apresentação dos temas, não foi solicitado que pesquisassem sobre a régua de cálculo, pois o intuito era utilizar o material no final das apresentações dos seminários, enfocando que as propriedades apresentadas podiam ser demonstradas concretamente. No entanto, foi possível trabalhar com a régua de cálculo logo no início, pois o assunto veio à tona, durante a explanação de um grupo que pesquisou sobre a história dos logaritmos.

Alguns alunos ficaram surpresos em saber que há tanto tempo um matemático foi capaz de chegar a uma invenção maravilhosa, mesmo com poucos recursos tecnológicos, com instrumentos parcos e muito trabalhosos, principalmente os instrumentos utilizados na navegação.

Estudar a história dos logaritmos possibilitou perceber que hoje os logaritmos são muito mais importantes do que o foram no momento de sua criação. Atualmente, os logaritmos não são utilizados somente para simplificar os cálculos, mas para a 
compreensão e a expressão de fenômenos em diferentes contextos, como por exemplo, nas medidas da intensidade sonora ou na medição da energia destruidora dos terremotos. Porém, no contexto escolar, para iniciar o processo de aprendizagem dos logaritmos, podem ser utilizados para a simplificação dos cálculos. Assim, o cálculo de uma multiplicação se transforma no cálculo de uma adição (dos expoentes) e o cálculo de uma divisão se transforma no cálculo no cálculo de uma subtração (dos expoentes). 


\section{Referências}

BOYER, C. B. História da Matemática. 3. ed. São Paulo: Blucher, 2010.

BRASIL. Ministério da Educação e do Desporto. Secretaria de Educação Básica. Orientações Educacionais Complementares aos Parâmetros Curriculares Nacionais $(\mathrm{PCN}+)$ : Ciências da Natureza, Matemática e suas Tecnologias. Brasília, DF: MEC, SEB, 2002. Disponível em:

<http://portal.mec.gov.br/seb/arquivos/pdf/CienciasNatureza.pdf>. Acesso em: 06 ago. 2013.

CÁLCULO. São Paulo: Segmento, out. 2013. n. 33.

CAMPAGNER, C. A. Como funciona a mãe da calculadora. [S. I.], [200-?]. Disponível em: < http://educacao.uol.com.br/matematica/regua-de-calculos-comofunciona-a-mae-da-calculadora.jhtm >. Acesso em: 01 dez. 2013.

EVES, H. Introdução à História da Matemática. Campinas, SP: Editora Unicamp, 2004.

GUIMARÃES, A. M. Calculando áreas, construindo tabelas e transformando produtos em somas: o que isso tem haver com os logaritmos? [S. I.], [200-]. Disponível em: <http://homepages.dcc.ufmg.br/ angelo/OficinaMAT/OficinaMat.html >. Acesso em: 04 dez. 2013.

LIMA, E. L. et al. A matemática no ensino médio. 9. ed. Rio de Janeiro: SBM, 2006. v. 1.

PAIVA, M. R. Matemática. São Paulo: Moderna, 2010.

PASTORE. G. Notícias históricas. [S. I.], [20--]. Disponível em:

<http://www.giovannipastore.it/index_portugues.HTM>. Acesso em: 01 dez. 2013.

SÃO PAULO (Estado). Secretaria da Educação do Estado de São Paulo. Caderno do Aluno: Matemática, Ensino Médio, $1^{\underline{a}}$ série, $3^{\circ}$ bimestre. São Paulo: SESP, 2013a.

Caderno do Professor: Matemática, Ensino Médio, 1aㅗ série, $3^{\circ}$ bimestre. São Paulo: SESP, 2013b. v. 3.

SOUZA, J. R. de. Novo olhar matemática. 1. ed. São Paulo: FTD, 2010. 


\section{ANEXO A - Texto entregue aos alunos durante a sequência didática}

O conceito de logaritmo apareceu como uma tentativa de simplificar o cálculo em uma época em que não existiam as calculadoras. Com os logaritmos as operações são substituídas por outras mais simples: potenciações por multiplicações, multiplicações por adições, divisões por subtrações.

Essas transformações de operações mais complicadas em operações mais simples são apresentadas na forma das seguintes propriedades:

1ㄹ propriedade: Logaritmo de um produto

O logaritmo de um produto é igual à soma dos logaritmos dos fatores, tomados na mesma base, isto é:

$$
\log _{b}(a . c)=\log _{b} a+\log _{b} c, \text { com } a>0, c>0 \text { e } 1 \neq b>0
$$

$2^{\text {a }}$ propriedade: Logaritmo de um quociente

O logaritmo de um quociente é igual ao logaritmo do dividendo menos o logaritmo do divisor, tomados na mesma base, isto é:

$$
\log _{b}\left(\frac{a}{b}\right)=\log _{b} a-\log _{b} c, \operatorname{com} a>0, c>0 e 1 \neq b>0
$$

$3^{\text {a }}$ propriedade: Logaritmo de uma potência

O logaritmo de uma potência é igual ao produto do expoente pelo logaritmo da base da potência, isto é:

$$
\log _{b} a^{n}=n \cdot \log _{b} a, \text { com } a>0,1 \neq b>0 \text { e } n \in R
$$


ANEXO B - Registro fotográfico da sequência didática aplicada a 31 alunos, na E.E. Dr. Francisco da Cunha Junqueira - Bonfim Paulista - Ribeirão Preto/SP.
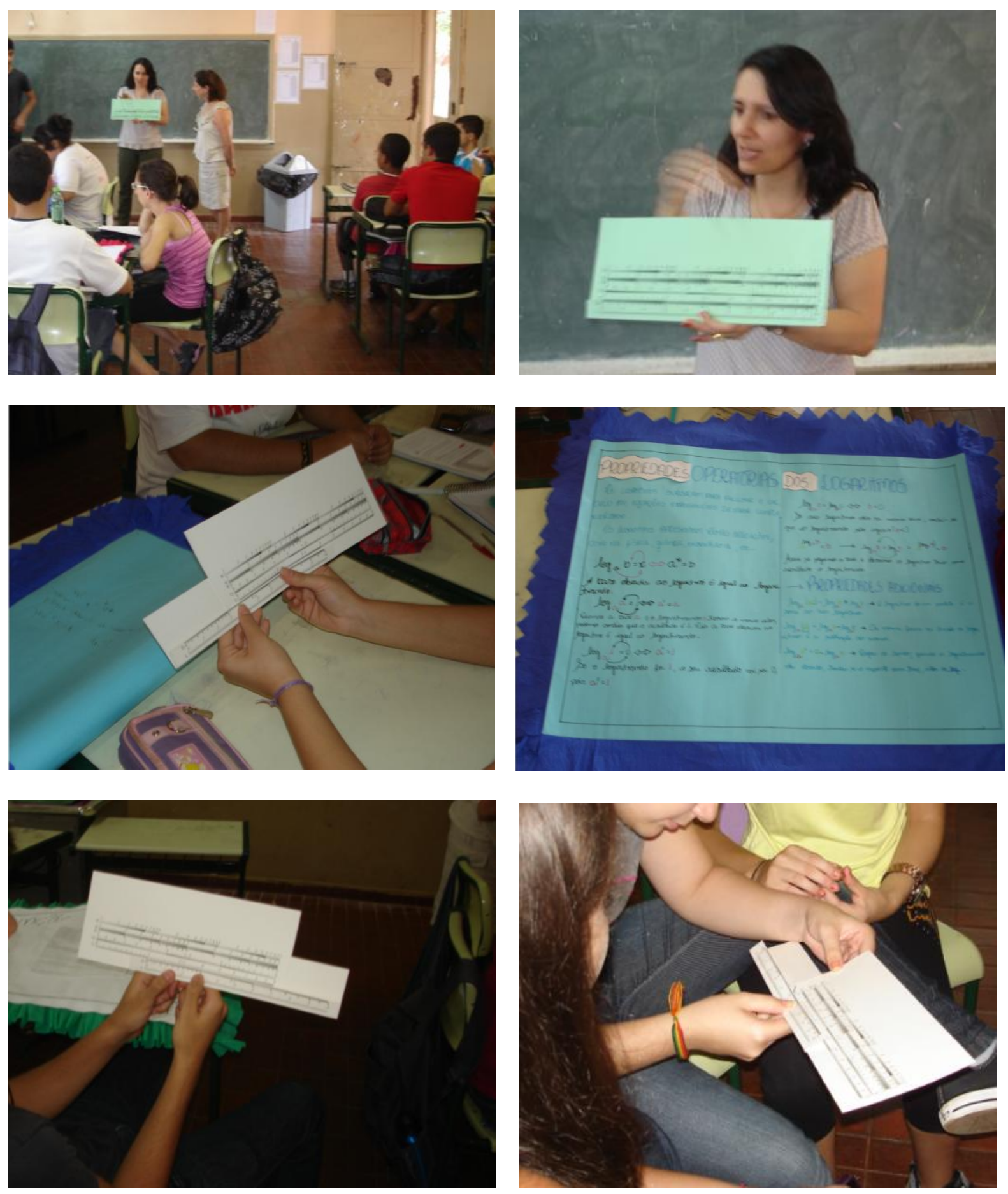

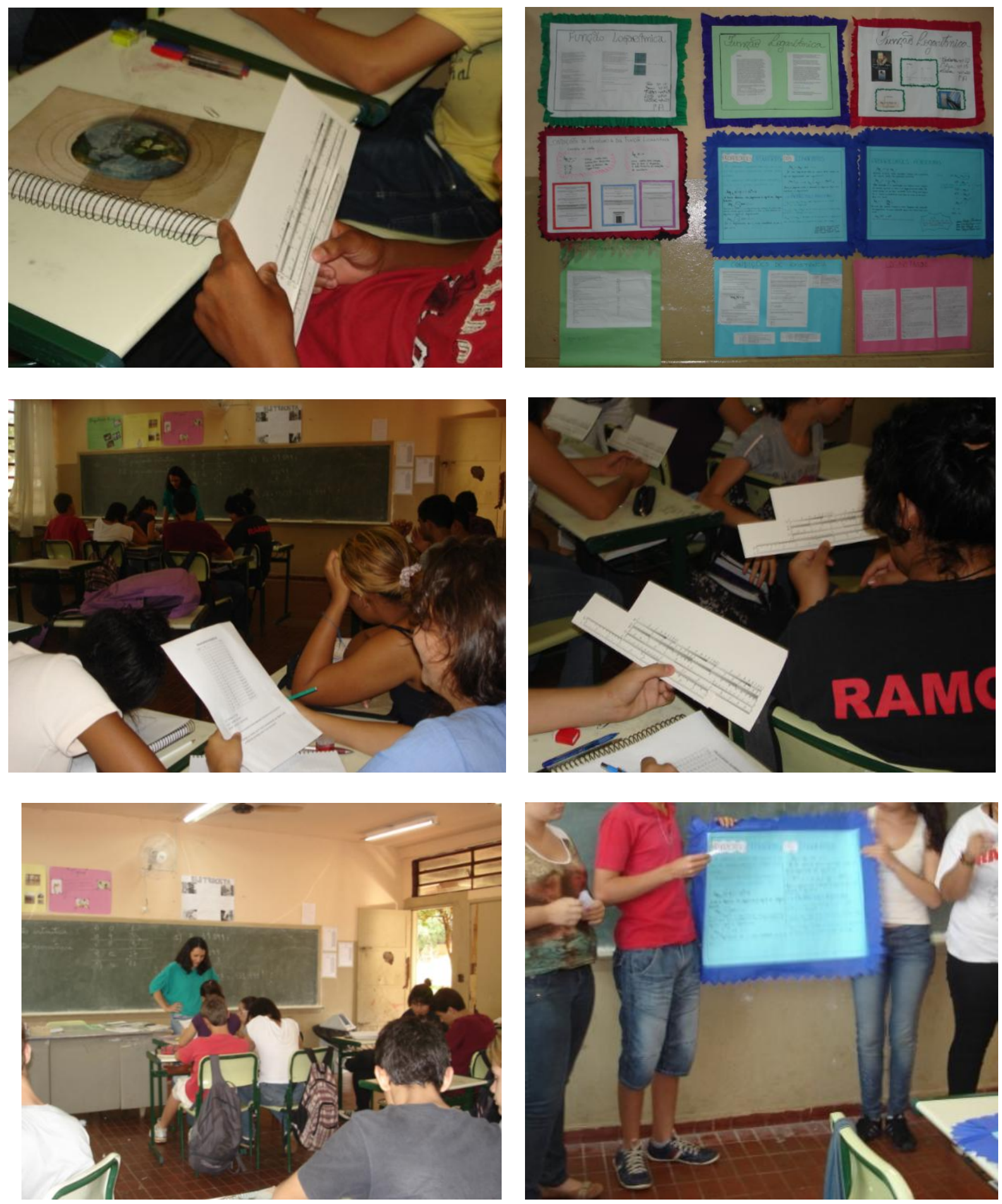
ANEXO C - Régua de cálculo utilizada pelos alunos durante a sequência didática realizada na E.E. Dr. Francisco da Cunha Junqueira - Bonfim Paulista - Ribeirão Preto/SP.

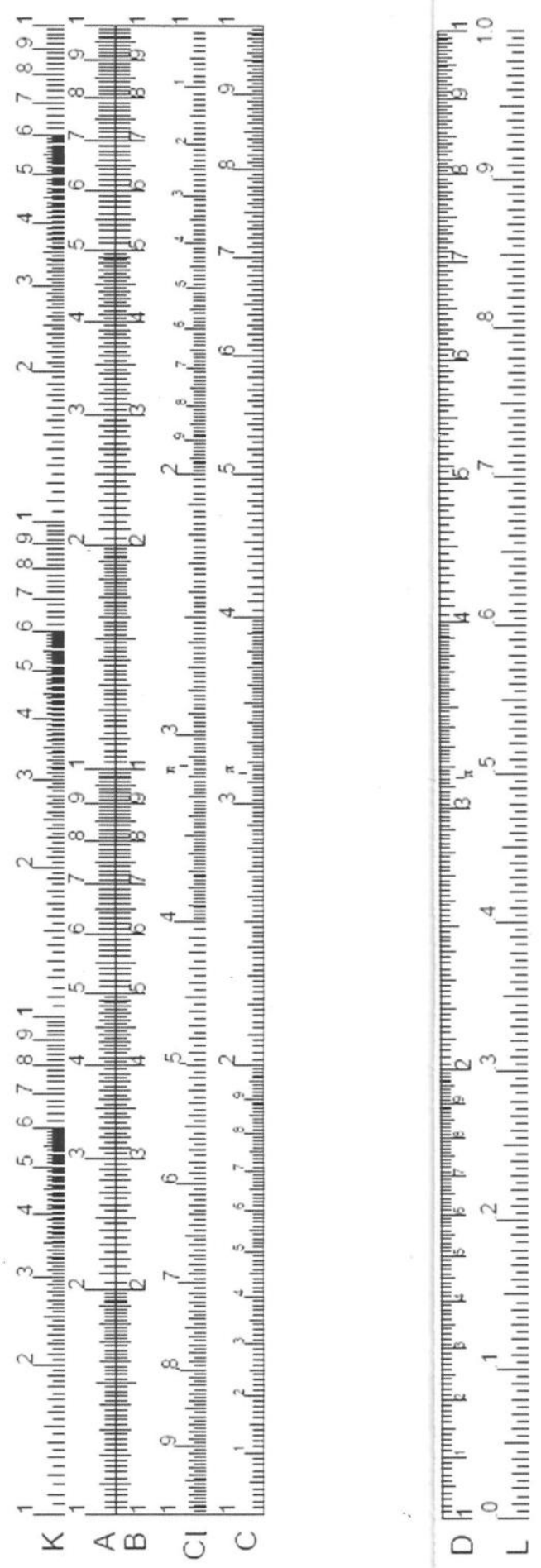


ANEXO D - Atividade realizada por dois alunos durante a sequência didática realizada na E.E. Dr. Francisco da Cunha Junqueira - Bonfim Paulista Ribeirão Preto/SP.

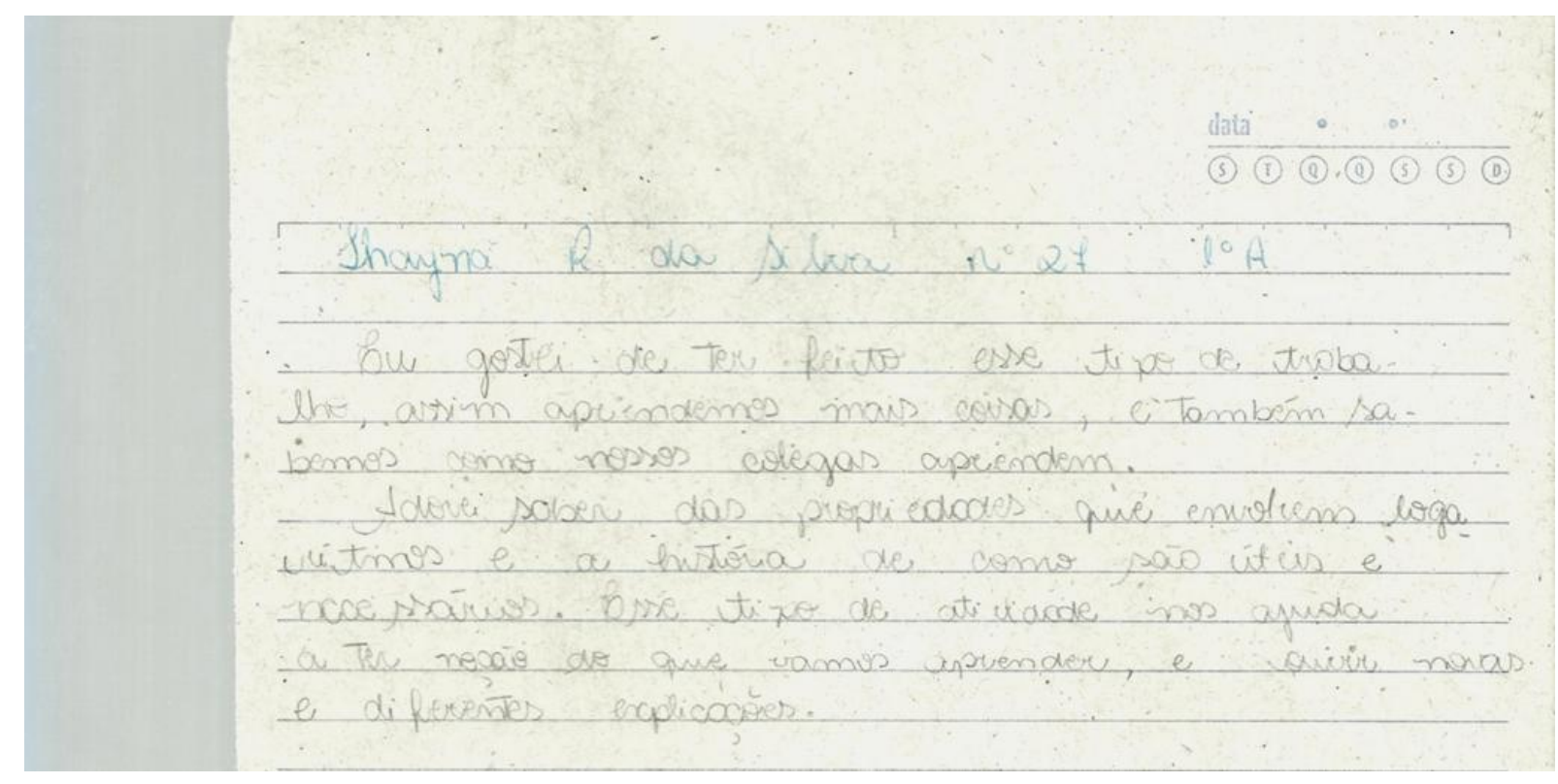




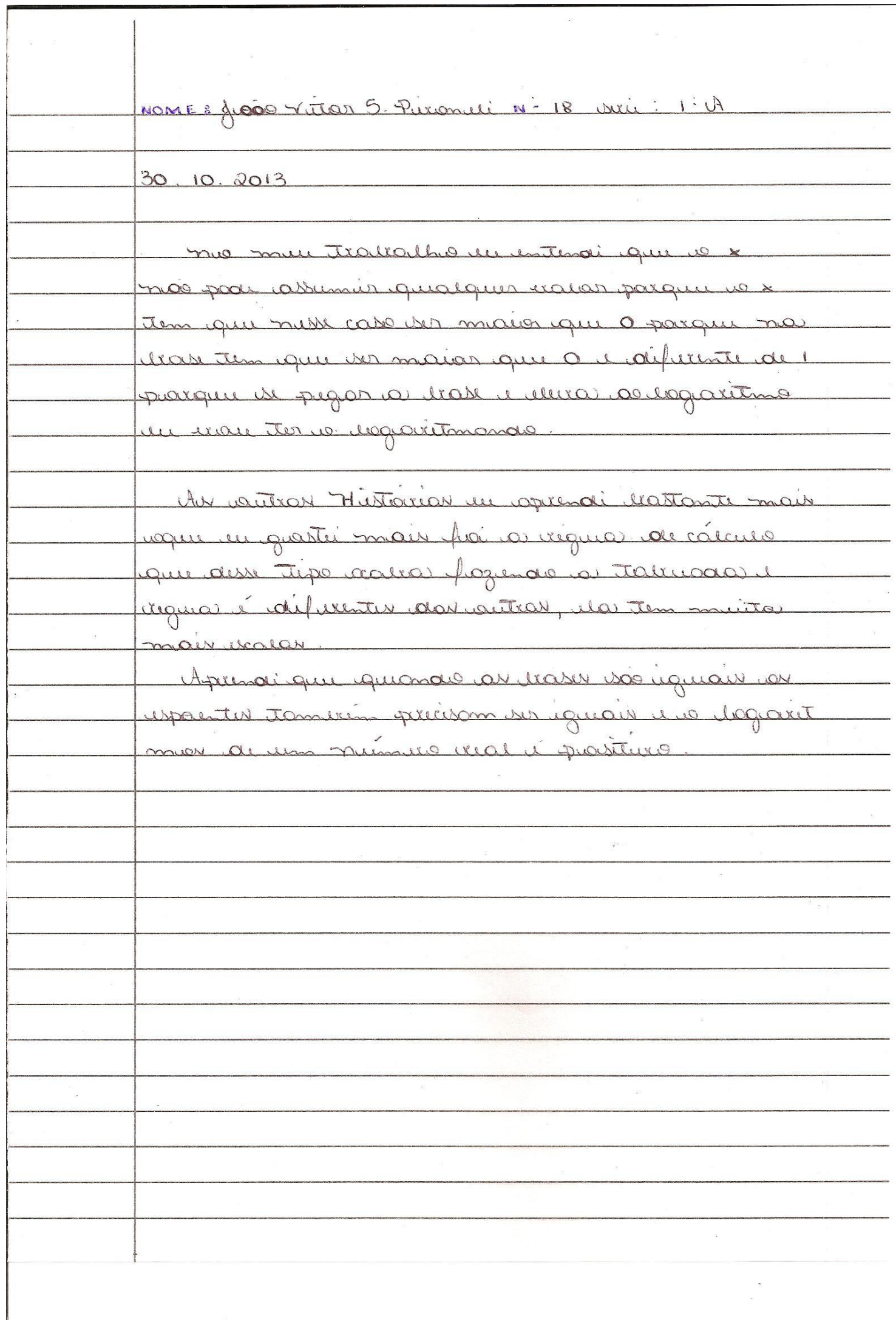




\section{E. E. DR. FRANCISCO DA CUNHA JUNQUEIRA}

\section{LOGARITMOS E A RÉGUA DE CÁLCULO}

Nome: Shayna Ribeiro da Sllo.

1) Para que serve a régua de cálculo?

Parios fozer operiaciós matemáticas rem is user de

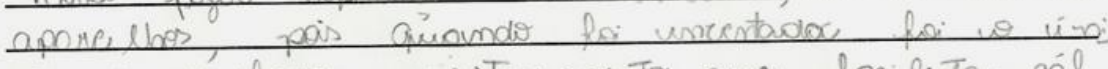

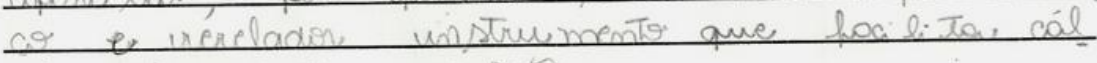
cules de grande, precionas.

2) A régua de cálculo ajuda no entendimento das propriedades dos logaritmos?

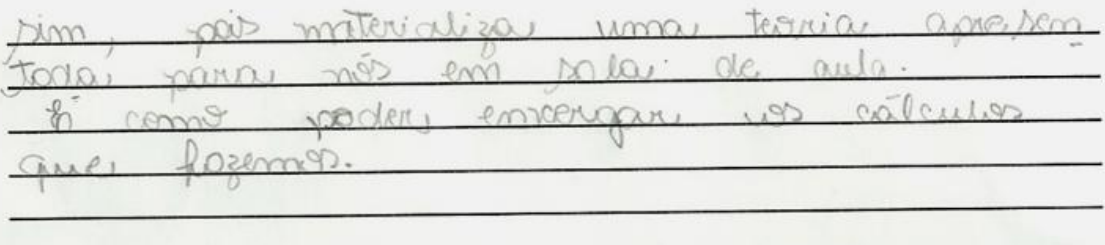

(1) wis da végua de cólculo foi ancerteza muito importante para is avance da matemaTica. Fo apartir deste instrumento que temos inge a calculodora, e que sobemos fozer todas as coperaciés matemáticas que temas. fं Tambèm bastan It usoda pelos engenhrios.

É um metodo diferente e interessonte de se pensare a matemát.ca. 
E. E. DR. FRANCISCO DA CUNHA JUNQUEIRA

LOGARITMOS E A RÉGUA DE CÁLCULO

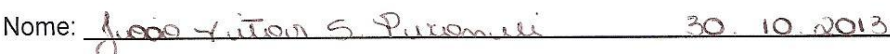

1) Para que serve a régua de cálculo?

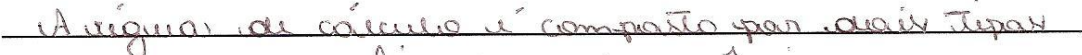

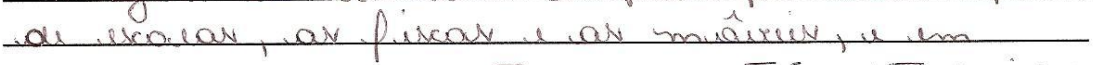

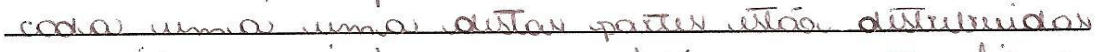

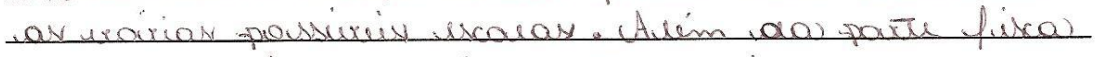

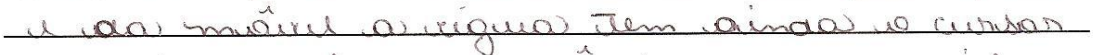

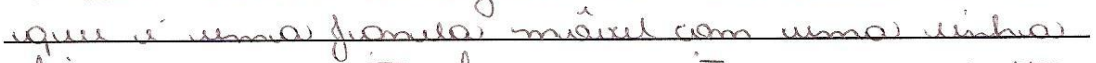

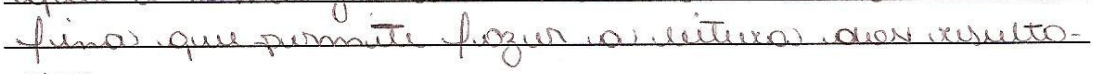
alovi

2) A régua de cálculo ajuda no entendimento das propriedades dos logaritmos?

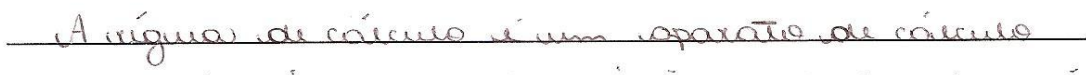

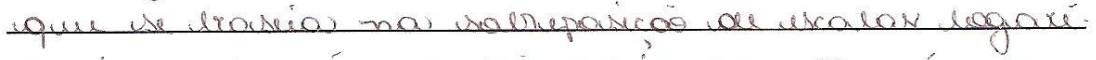

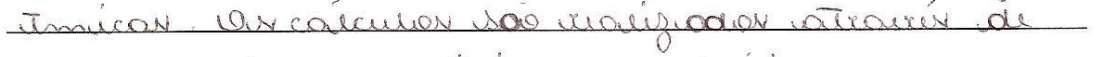

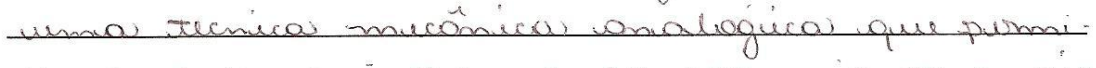

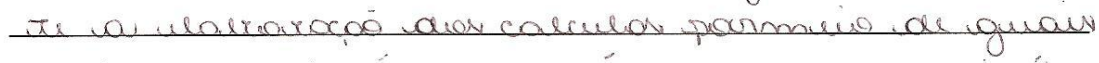

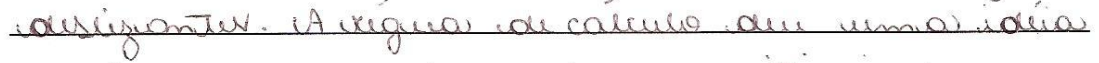

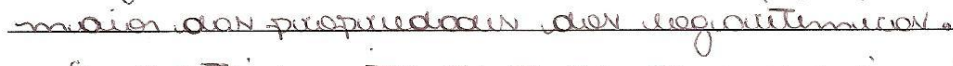

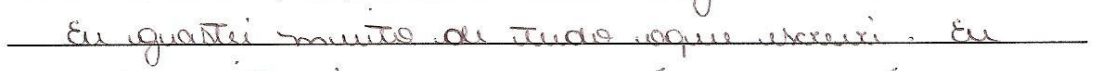

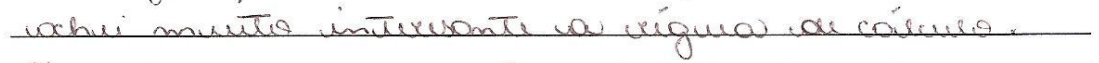

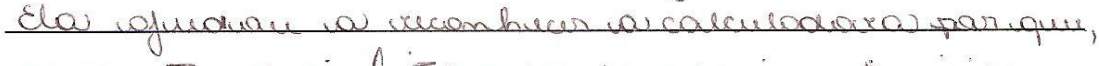

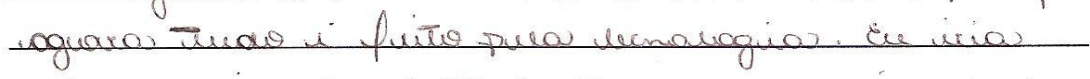

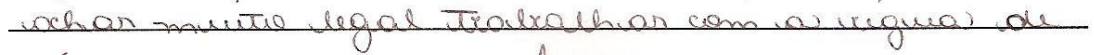

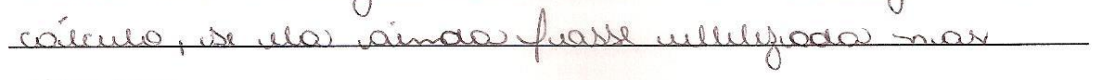
Wacour. 